$$
\begin{aligned}
& \text { اثرتوظيف الواقع الافتراضي في الممارسات الاكاديمية المعمارية } \\
& \text { شذى يعقوب الشيخ - استاذ مساعد } \\
& \text { vacoubshatha@yahoo.com } \\
& \text { نعم بهنام منونة - مدرس }
\end{aligned}
$$

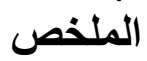

لقد عدت التقتيات المرتبطة بالواقع الافتراضي ، من الهم المخرجات الخاصة بالثورة الرقمية وتداعياتها التكنولوجية،

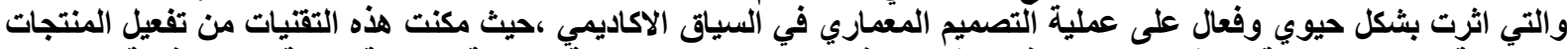

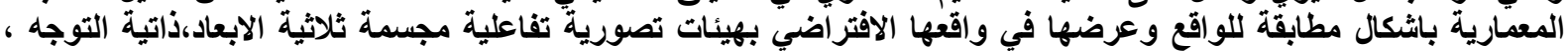

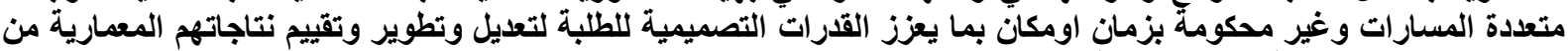

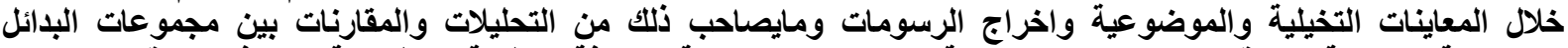

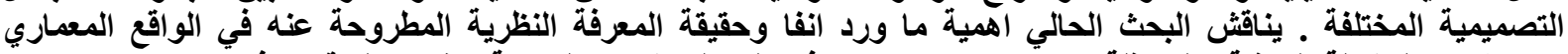

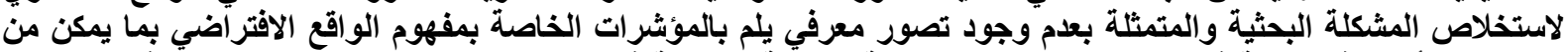

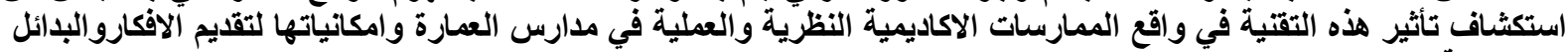
التصميمية المبتكرة.

وبناءا على هذه الاشكالية البحثية فقد هذف البحث الكثف عن ذلكئل وتسليط الضوء على الابعاد النظرية لهذه التقتية

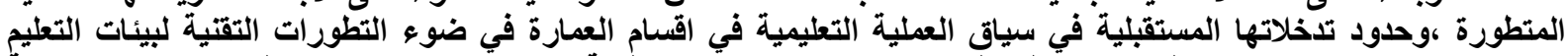

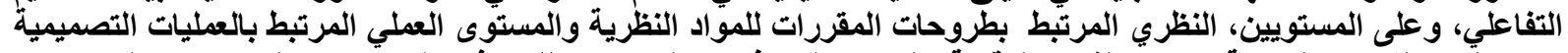

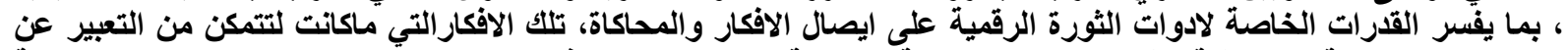

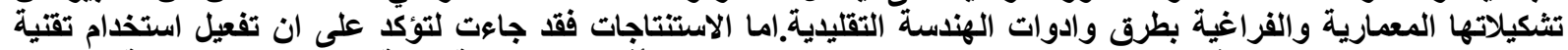

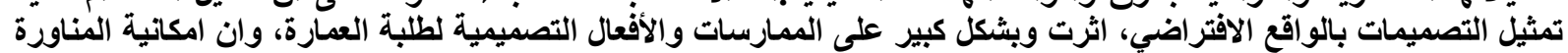

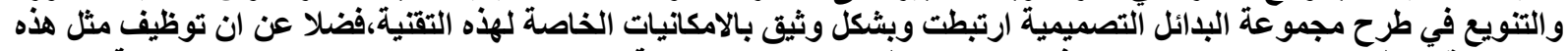

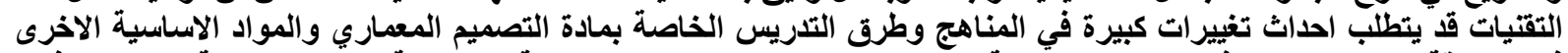

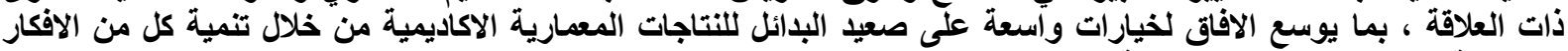
الابتكارية والحس التجريبي لاى طلبة العمارة.

\title{
The Effect of Employing Virtual Reality in Architectural Academic Practices
}

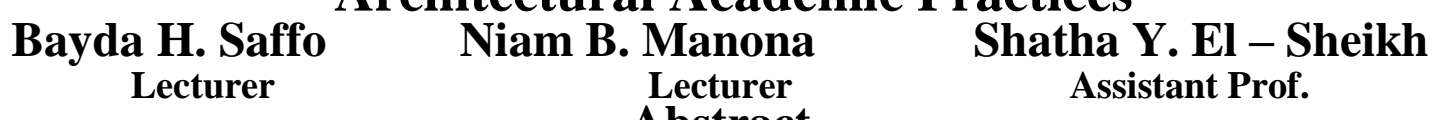

Abstract

This study deals with investigating the epistemological aspects related to the virtual reality techniques. Which are considered as the most important outputs of the digital revolution and its impact vitally the architectural design process in the academic context, reinforcing students design capacity to modulate, develop and estimate their architectural products, as well as producing drawings, analyzing and comparing between different design alternatives. The research discusses the importance of the subject, in order to conclude the research problem which is represented by unclarity of the effect of this technique in both practical and theoretical academic practice in schools of architecture, as well as, their abilities to present creative design alternatives and ideas. The study aims to concentrate on the theoretical aspects of this developed technique and the dimensions of its future intervention on teaching process, in a way that explains the capabilities of the digital revolution tools that communicate the ideas and simulation. The research concluded that, presenting designs by employing the virtual reality techniques affected largely design practice of architectural students. And the capabilities of presenting many design alternatives were connected strongly with capabilities of this technique, as the employment of these, may requires great changes in both curricula and teaching ways of architectural design subject and other subjects, in a way that expands choices of alternatives and innovative ideas for architectural academic products .

Key words: virtual reality, digital revolution, architectural teaching

$$
\text { قبل: } 2013 \text { - } 10 \text { - } 8
$$

أستلم: 2013 - 6 - 6 


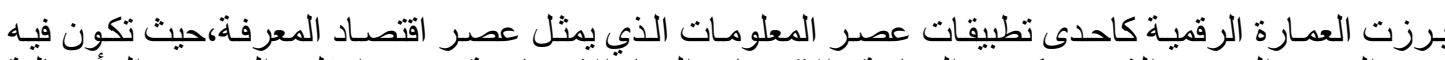

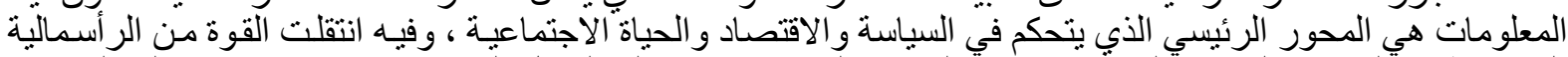

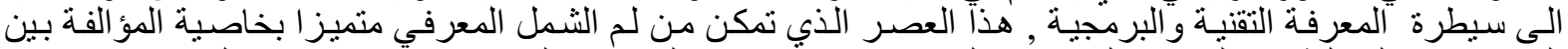

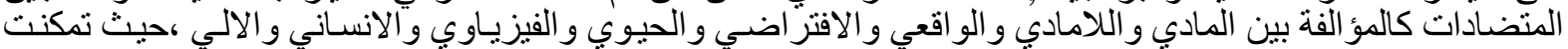

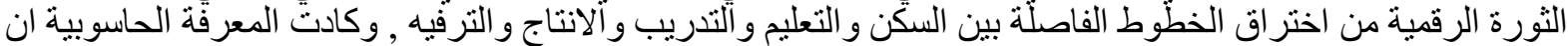

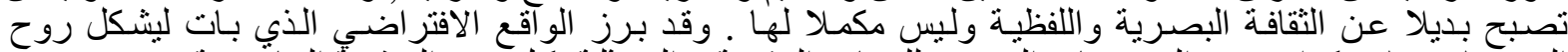

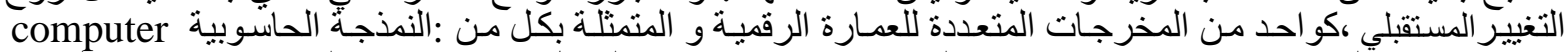

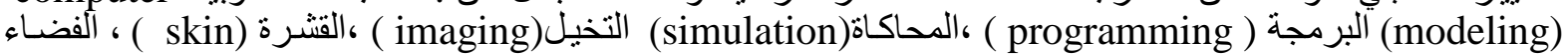
الافنتر اضي (2012/p.7-9/ El Shami ). ( cyberspace)

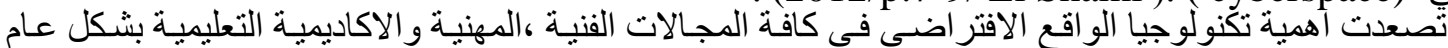

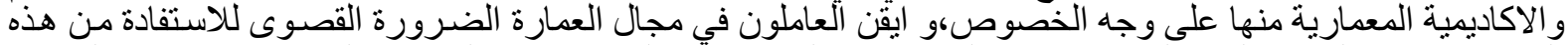

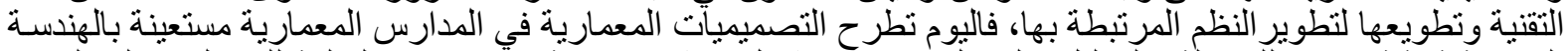

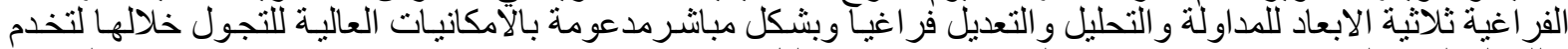

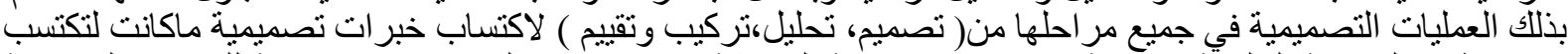

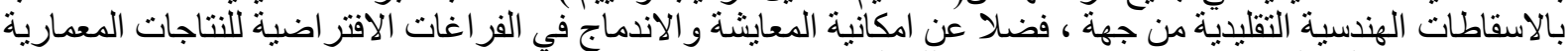

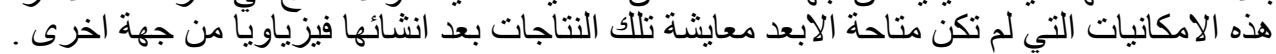

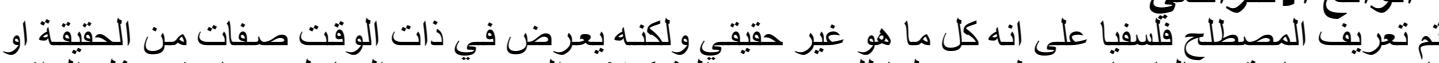

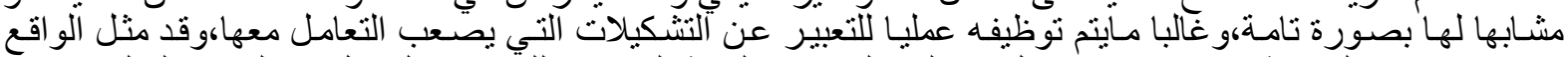

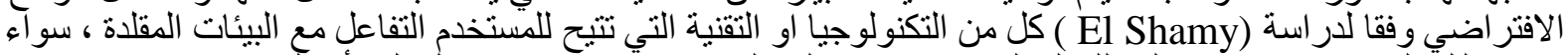

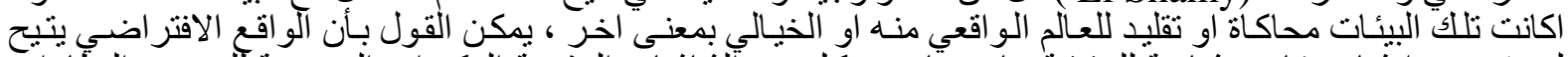

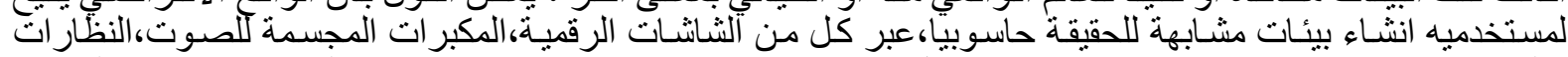

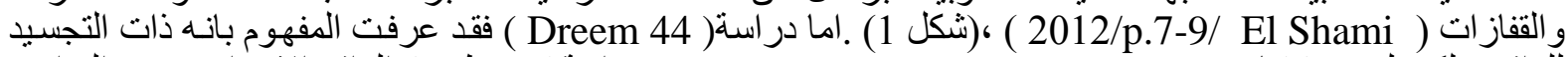

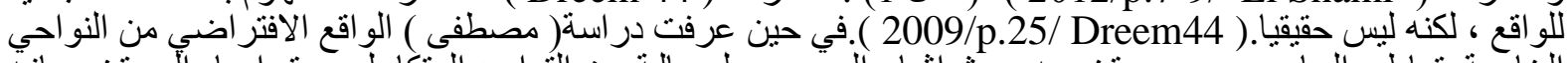

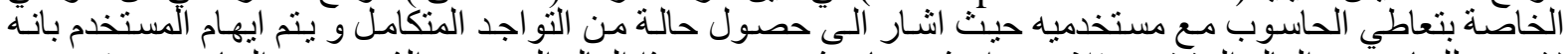

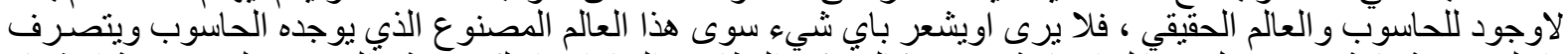

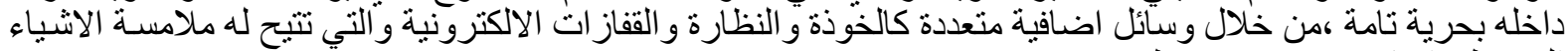

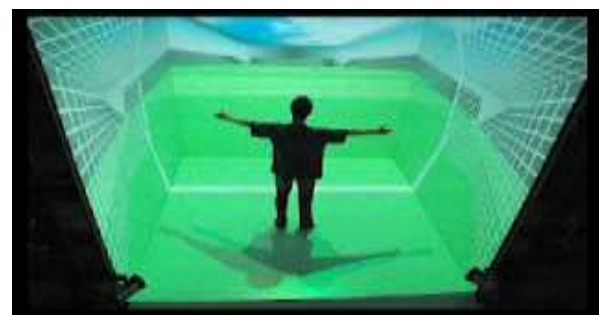

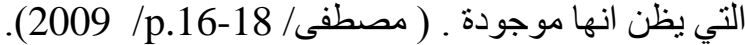

(Virtual reality space )

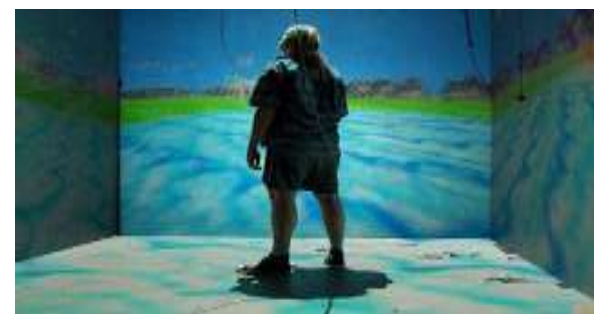

( شكل 1 ) فضاءات الو اقع الافتراضي ــ تقنية التخيل (2012/p.7-9/ El Shami )

اما دراسة (اديب) فقد لاحظ في دراسته ان الو اقع الافتر اضي، فضاءا رمزيا (cyberspace ) ناشئًا من استخدام

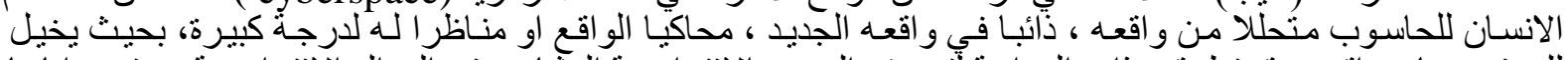

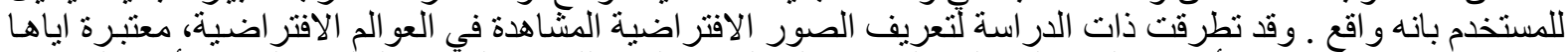

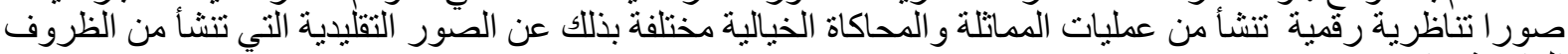

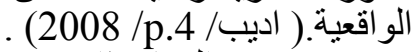

وفي السياق ذاته وصفت دراسة (Omran) عن (الخباز) ماهية الو اقع الافتر اضي من ناحيـة كل من المستخدم

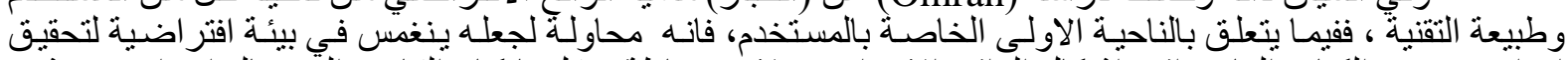

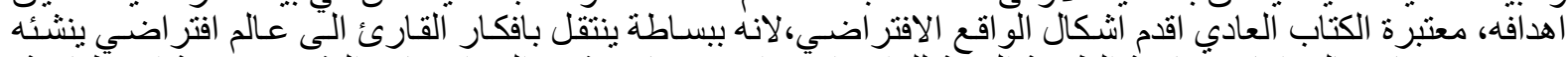

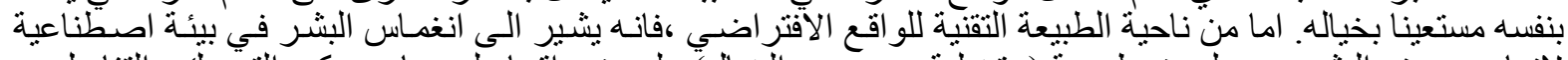

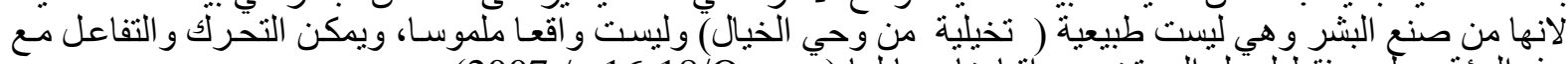

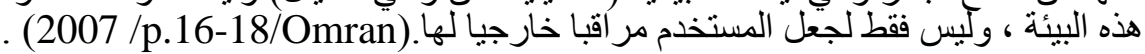




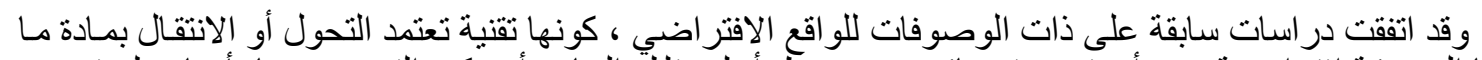

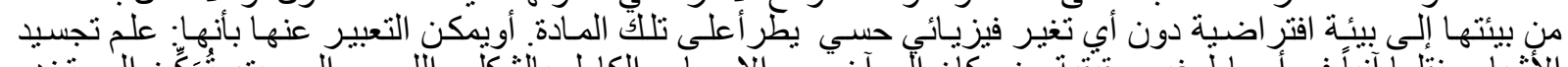

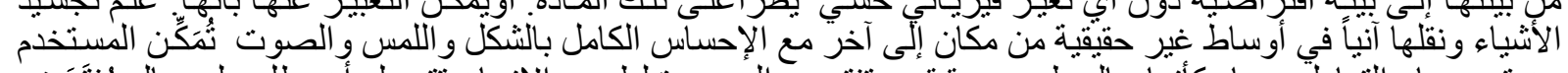

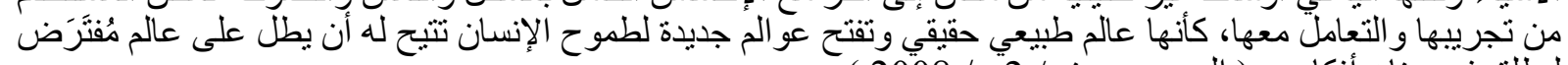

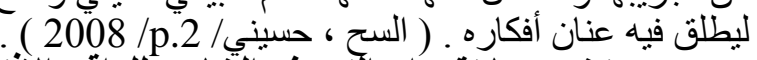

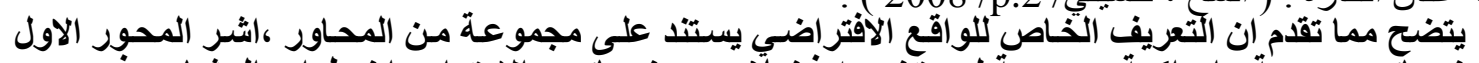

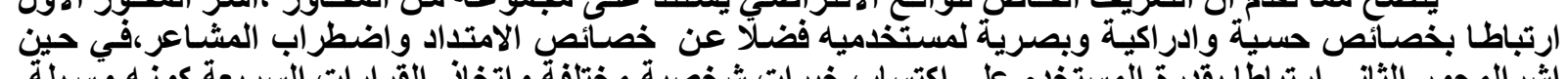

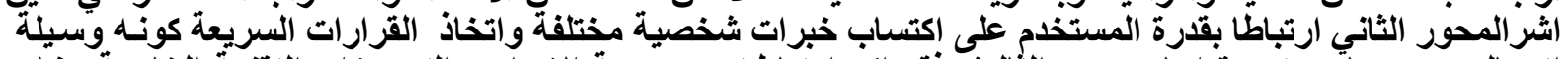

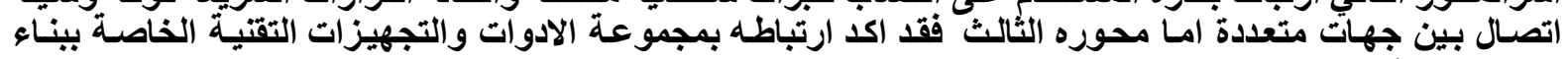
عروضه ومشاهداته .

\section{3- اهمية تقتية الواقع الافتر اضي ومجالات توظيفه}

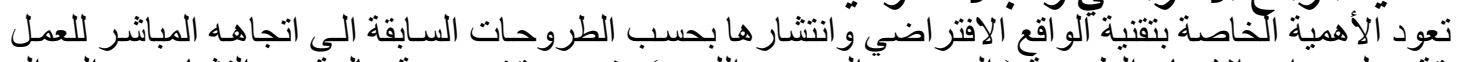

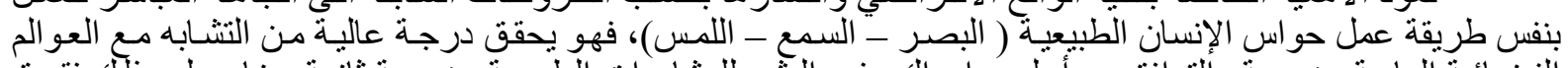

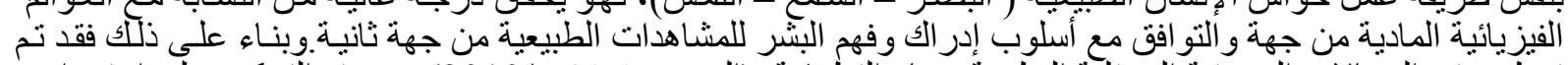

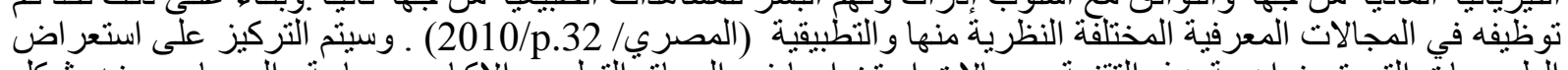

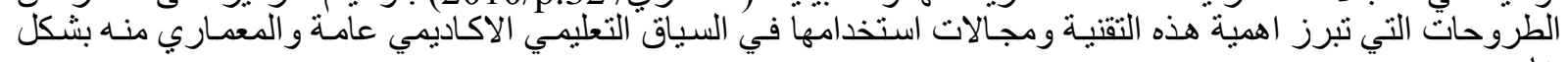

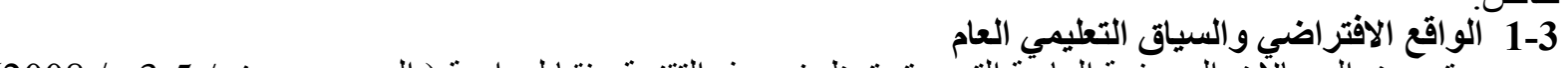

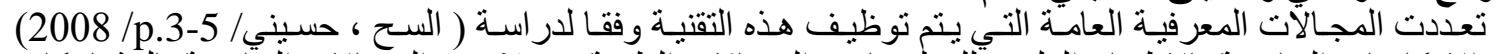

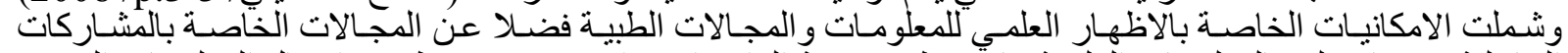

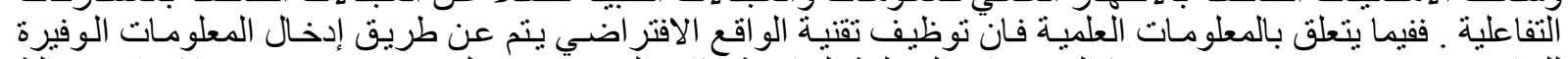

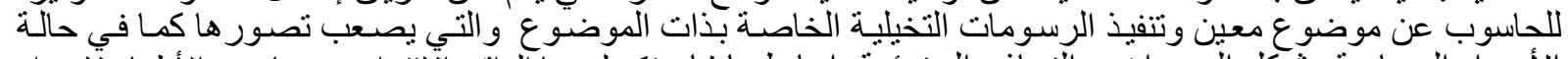

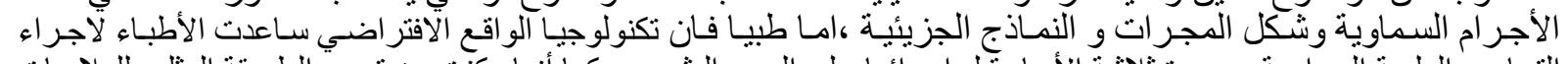

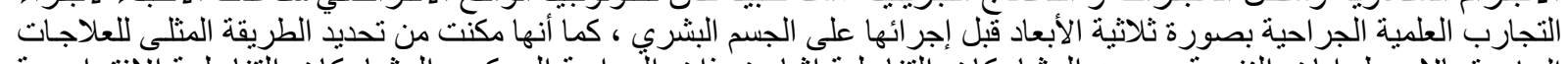

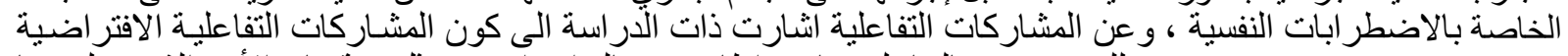
collaborative virtual

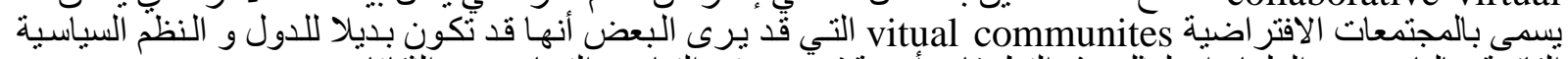

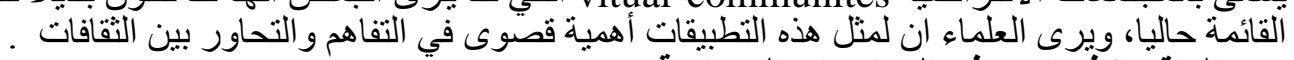

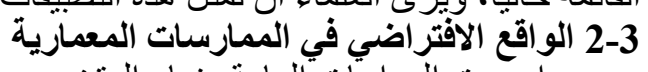

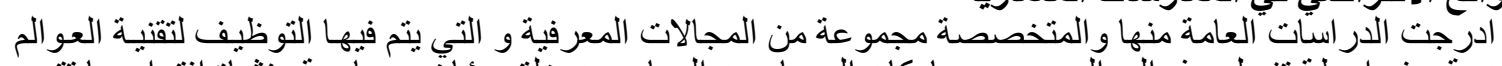

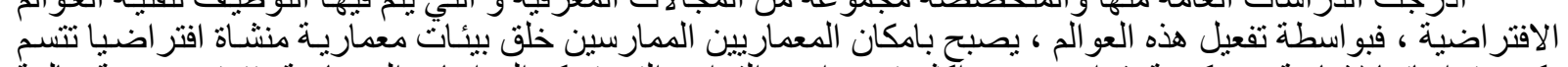

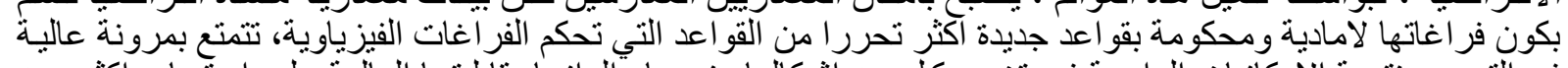

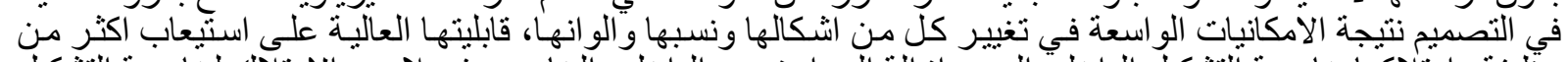

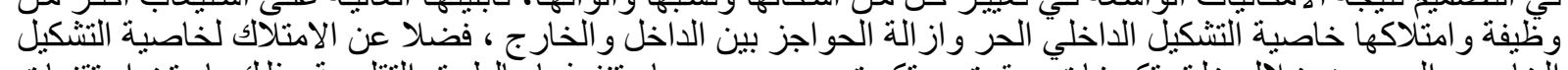

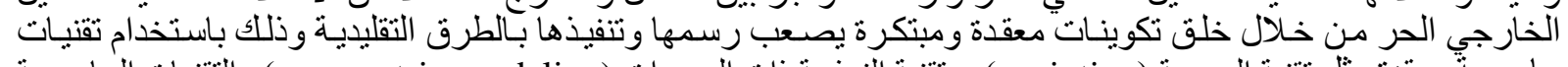

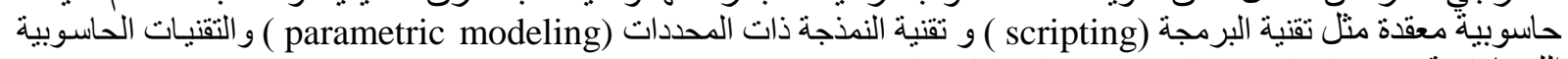

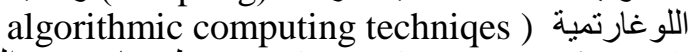

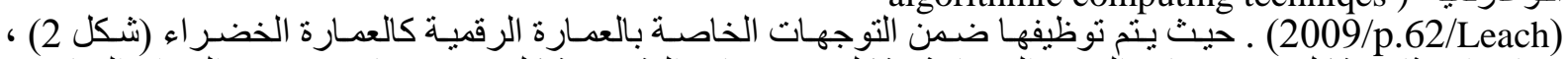

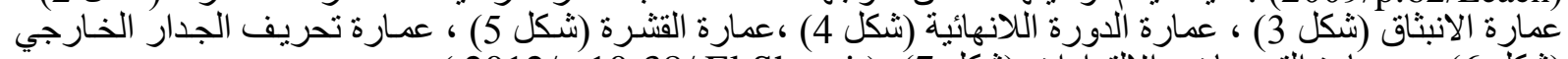
(شكل 6) ، وعمارة التموجات والالتو اءوات (شكل 7). (2012/p.10-38/ El Shami ).

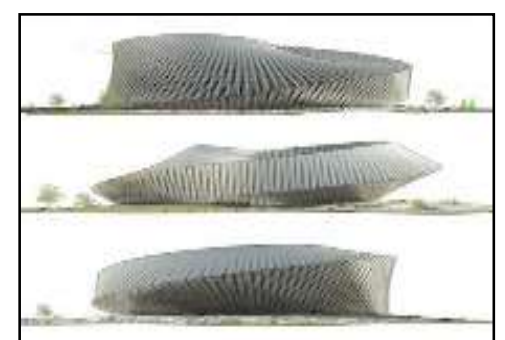

(شكل 4) عمارة الحلقة اللانهائي

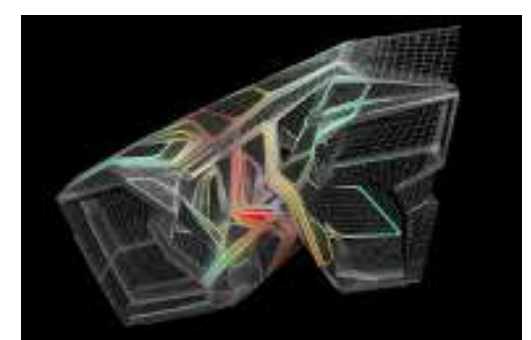

( شكل 3 ) عمارة الانبثاق (2012/p.10-38/ El Shami )

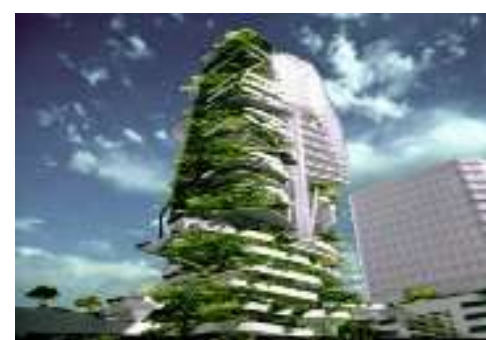

( شكل 2 ) العمارة الخضر اء 

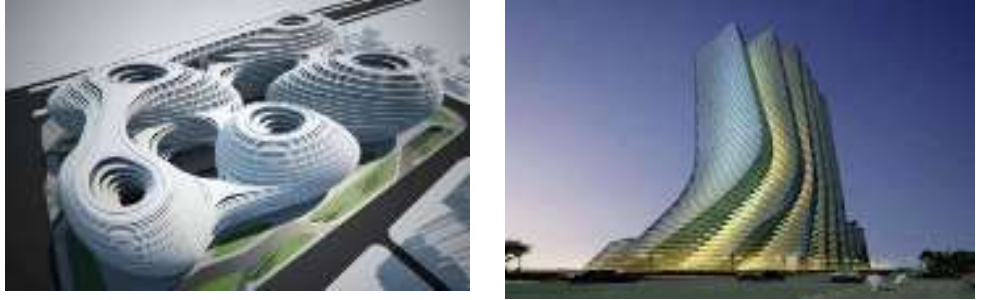

(شكل 6) عمارة تحريف الجدار (شكل 7) عمارة التموجات و الالتو اءات (2012/p.10-38/ El Shami )

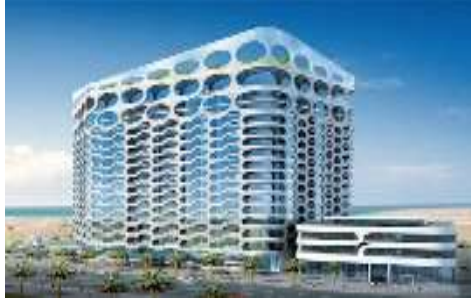

(شكل 5) ممارة القشرة

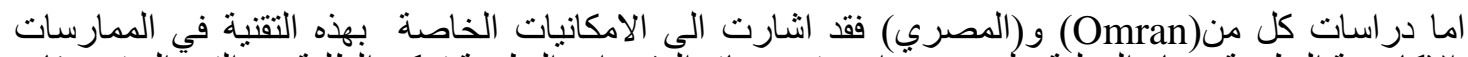

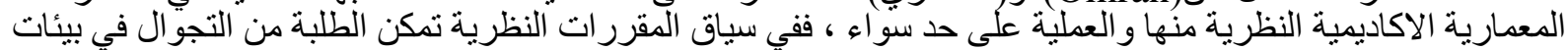

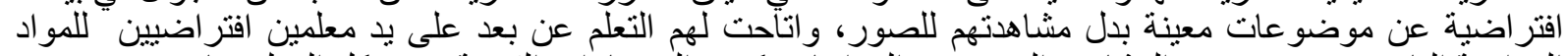

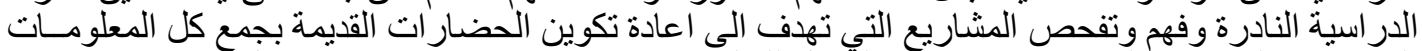

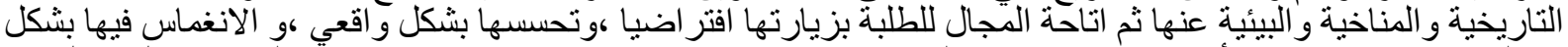

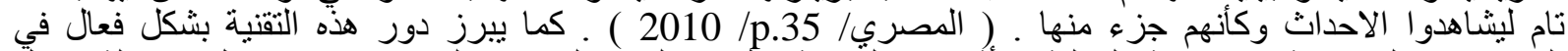

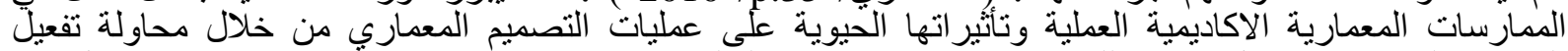

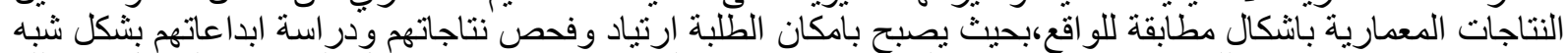

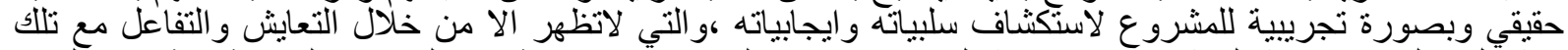

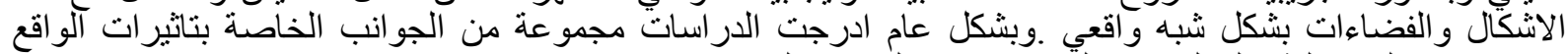

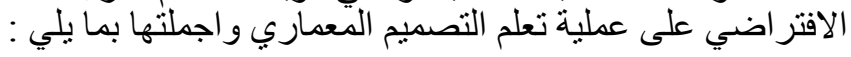

1- تقييمات لتشكيلات المباني و اشكال الكتل الخارجية و الفراغات بينها و علاقتها مع السياق المجاور . .

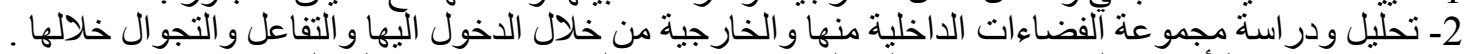

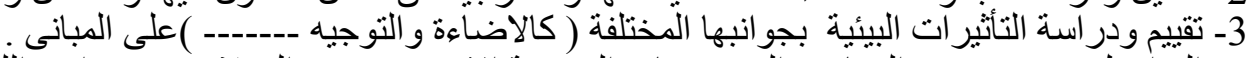

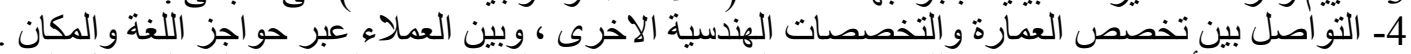

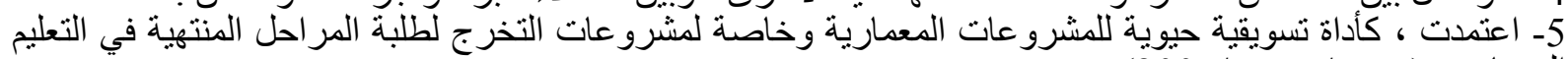

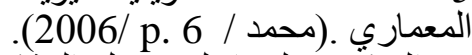
6- التركيز على اسلوب حل حل المشكلات التصميمية بدرجة اكبر (problem solving) وبدرجة اقل على على المحاضرات

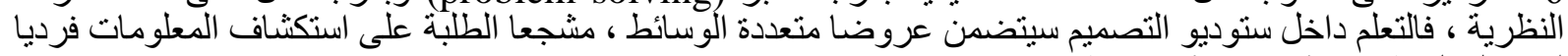

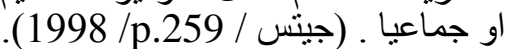

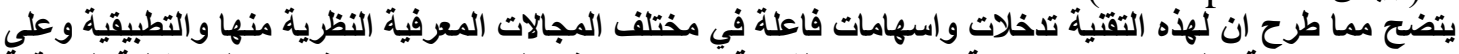

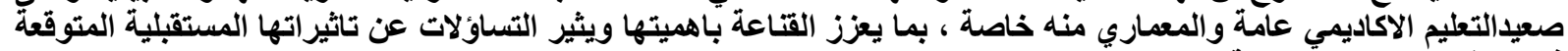
في سياقات التعليم المعمارية.

\section{3-3 الواقع الافتراضي في الطروحات النظرية}

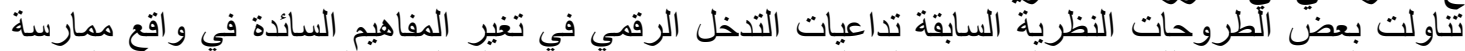

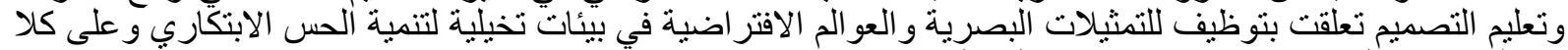

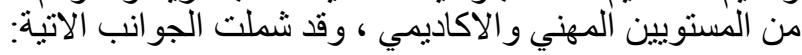

1- مناقثة ناثنير تكنولوجيا التصميم الرقمية على اعمال المعماريين العالميين من خلال استقراء العلاقة بين التكنولوجيا

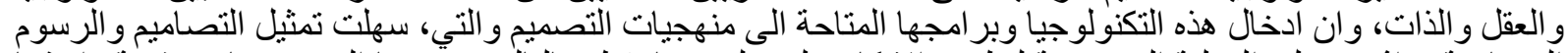

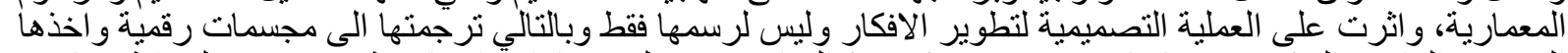

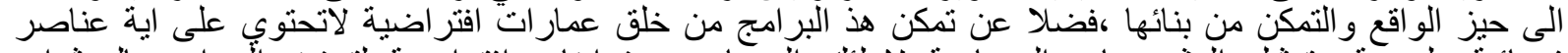

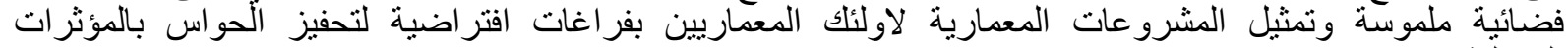
المختلفة. (1992/p.55-56/ Douglas).

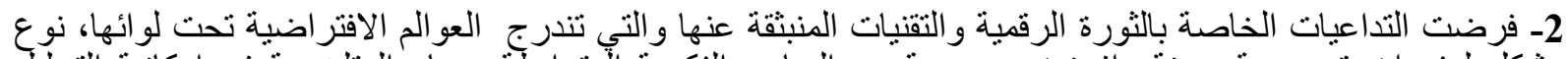

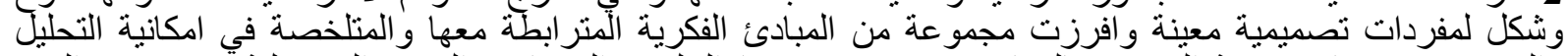

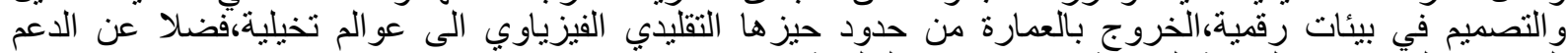
اللامحدود للآتجاهات الفكرية التفردية والافكار غير التقليدية.(محمد/12.12006/p). 
3- نسليط الضوء على العلاقة بين تفعيل التوظيف للعو الم الافتر اضية، وبين تنتمية القدرات الاستيعابية والابتكارية و اتخاذ

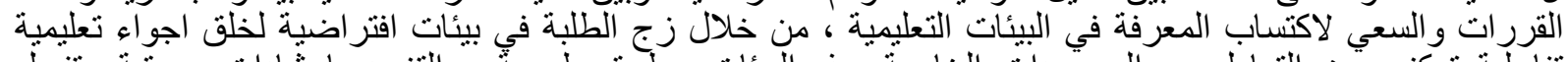

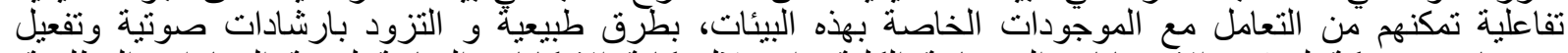

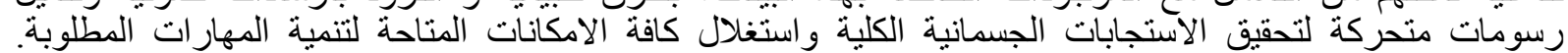
.(2002/p.15/Schwienhorst)

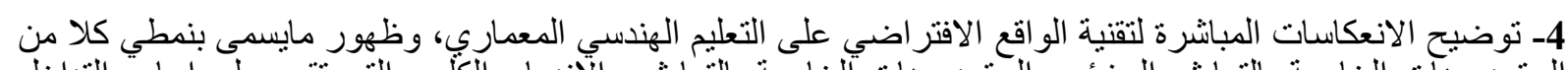

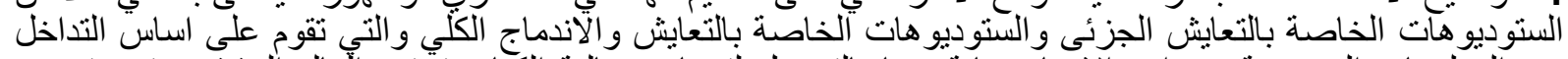

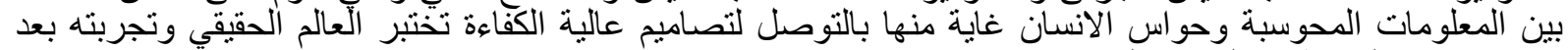

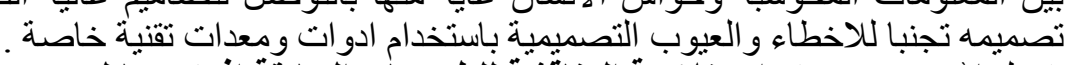

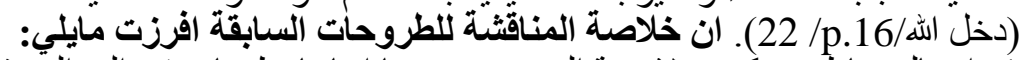

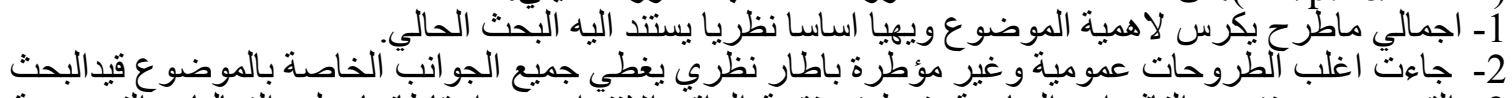

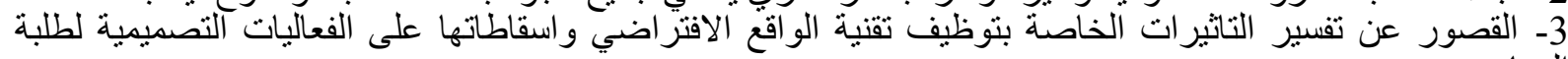

\section{4- استخلاص المشكلة البحثية}

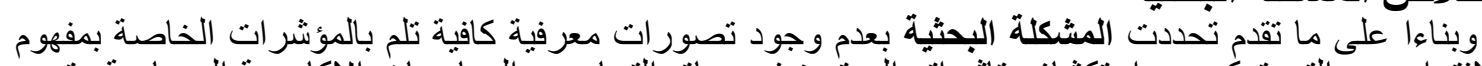

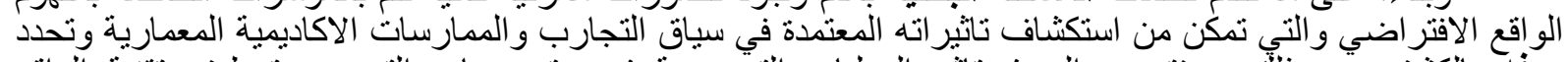

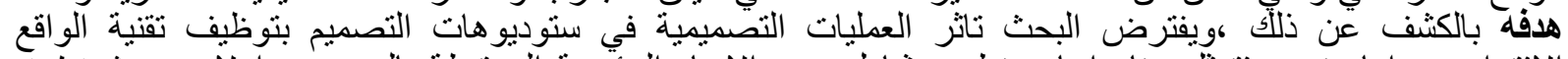

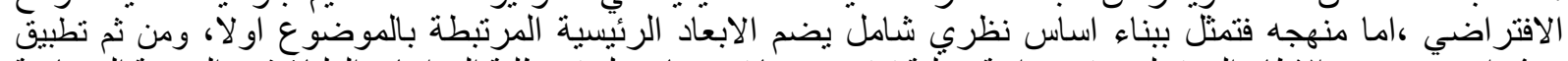

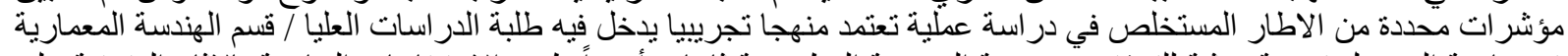

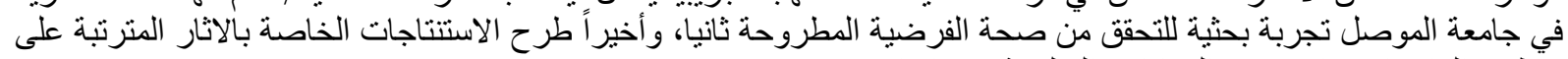
توظيف الو اقع الافتراضي في السياقات التعليمية ومدياتها.

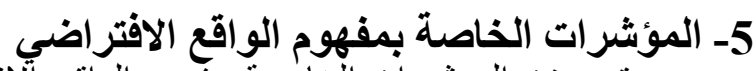

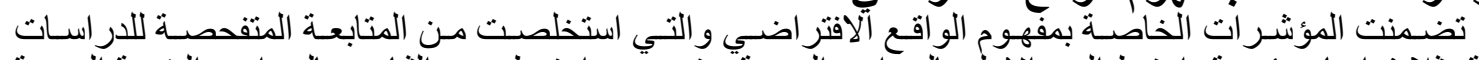

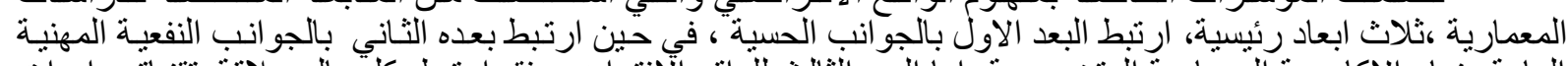

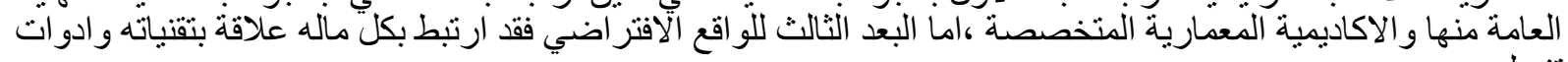

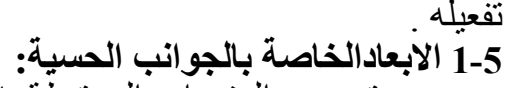

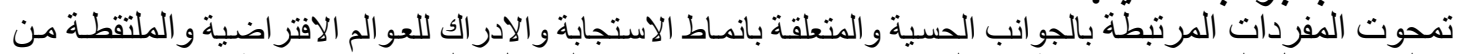

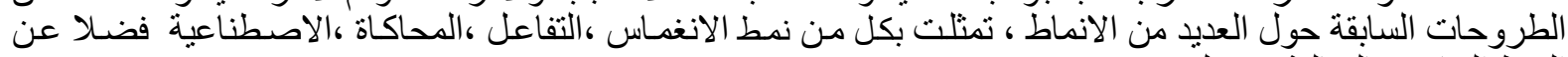

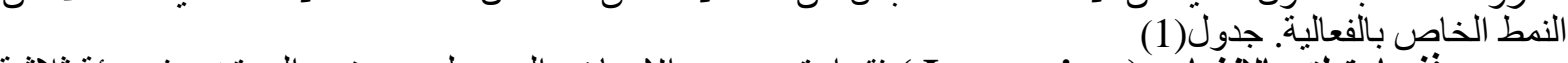

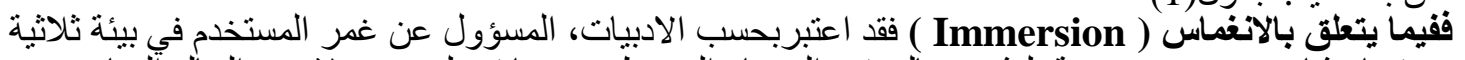

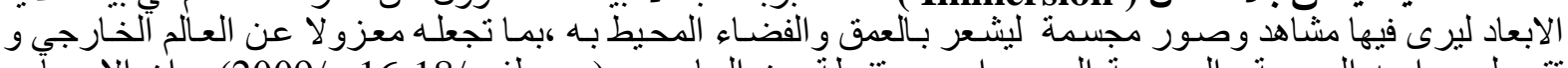

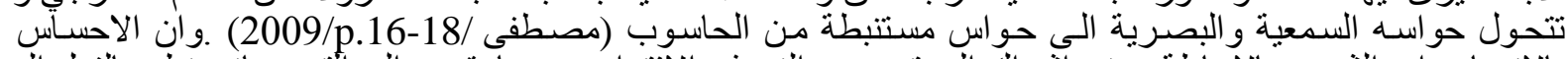

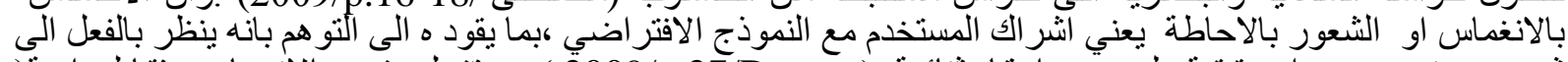

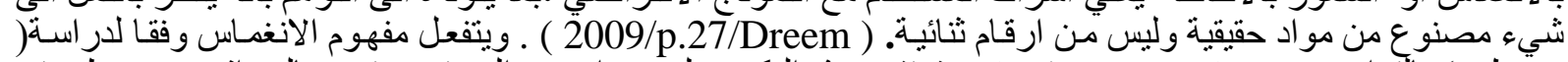

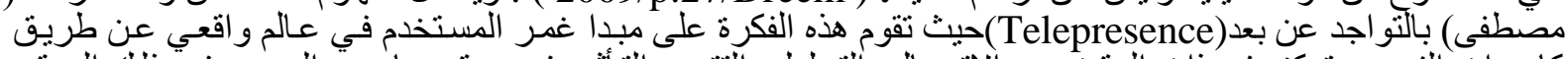

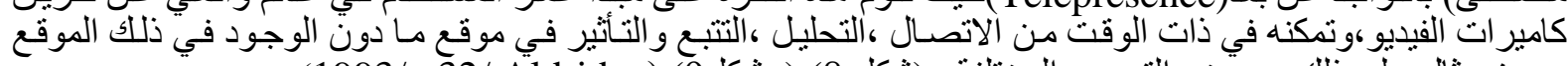

وييرز مثال على ذلك عروض التصميم المختلفة ـ (شكل 8) ( شكلو (1993/p.32/ Aldridge) .

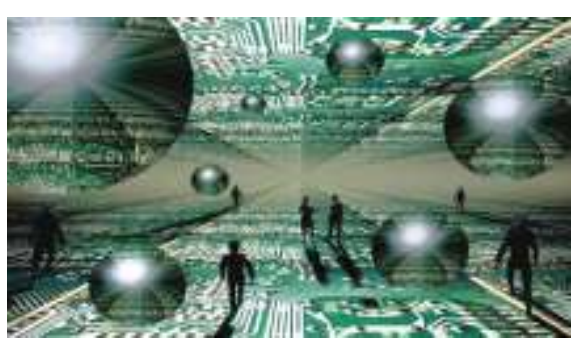

( شكل 9) الانغماس في الو اقع الافتر اضي
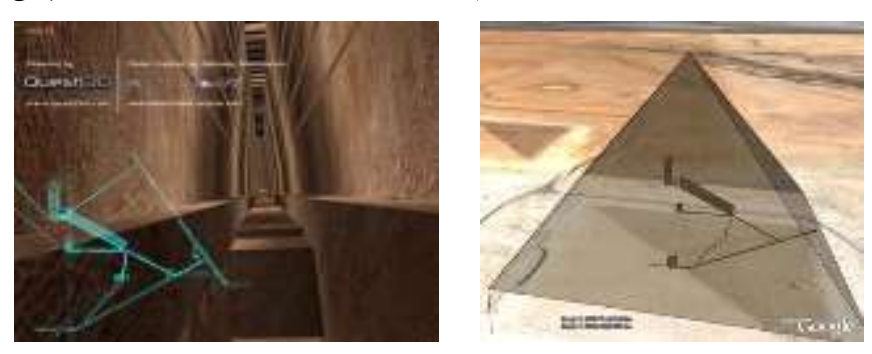

(شكل 8) استكثاف الممرات الداخلية لاهرام الجيزة

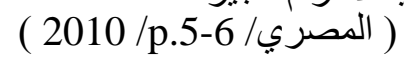




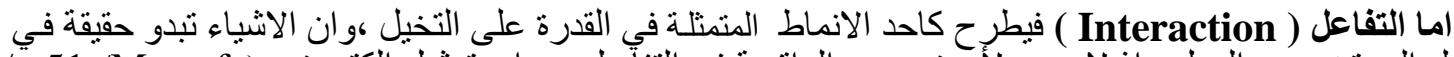

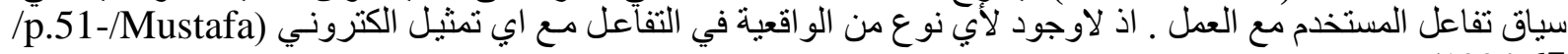
1994 67

وتبرز المحاكاة ( Simulation ) واحدة من الانماط المهمة التي تفسر تقنيـة الو اقع الافتر اضي حيث ارتبطت

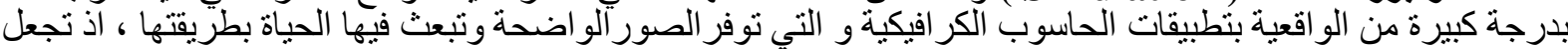

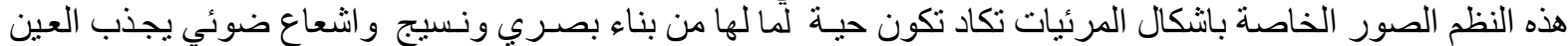

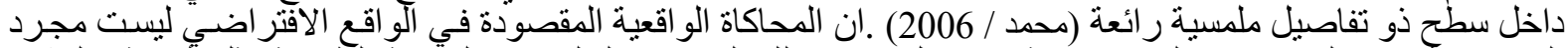

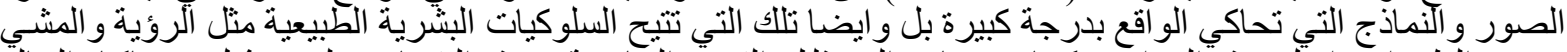

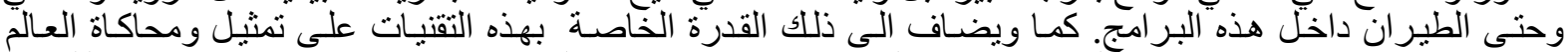

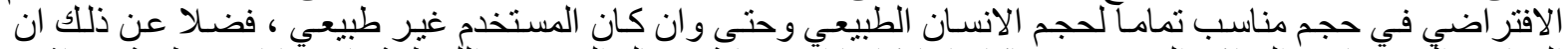

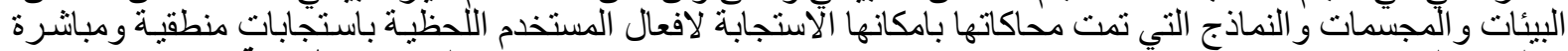

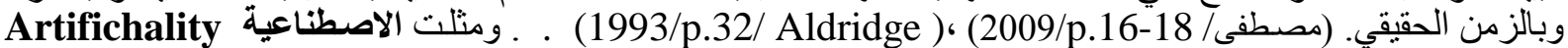

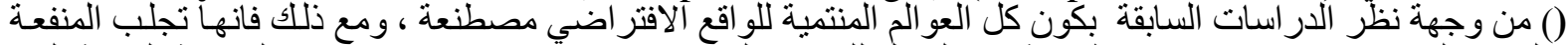

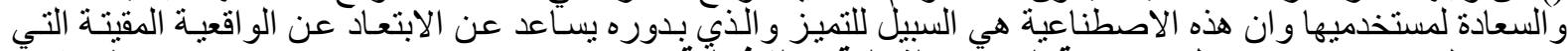

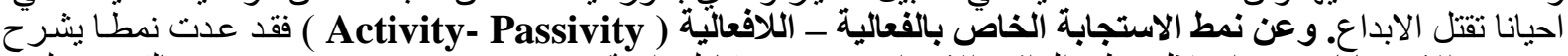

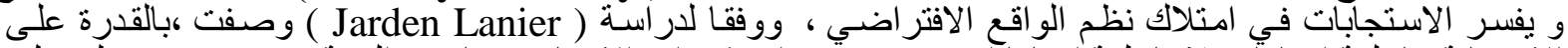

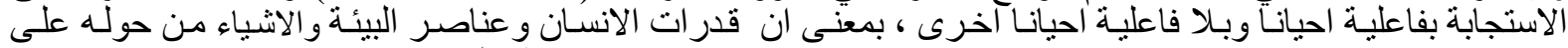

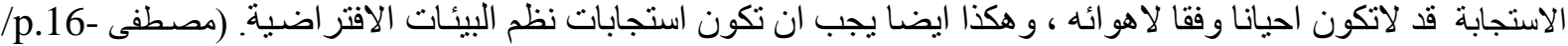

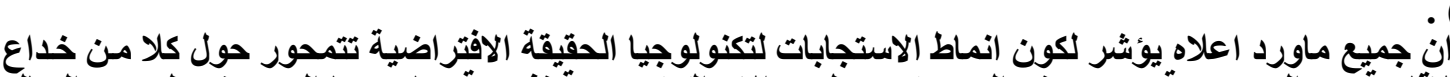
(200918

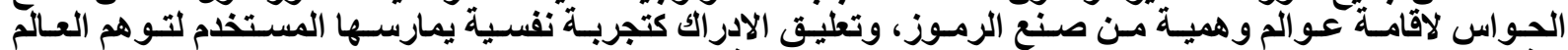

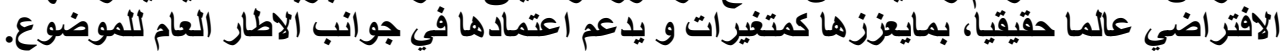

\begin{tabular}{|c|c|c|c|}
\hline \multicolumn{2}{|c|}{ القيم الممكنة } & المتغيرات الرئيسية & 1 \\
\hline \multicolumn{2}{|c|}{ المشاهد مجسمة } & \multirow[t]{5}{*}{ الانغماس } & \multirow{22}{*}{$\frac{E}{E}$} \\
\hline \multicolumn{2}{|c|}{ الإحساس بالفضـاء } & & \\
\hline \multicolumn{2}{|c|}{ الانعز أل عن العالم الخارجي } & & \\
\hline \multicolumn{2}{|c|}{ الحو اس المتحولة } & & \\
\hline \multicolumn{2}{|c|}{ التواجد عن بعد } & & \\
\hline التو اجد في أماكن حقيقية & \multirow[t]{5}{*}{ قدر ات تخيلية } & \multirow[t]{6}{*}{ التفاعل } & \\
\hline التو اجد في أَماكن غير حقيقة & & & \\
\hline التو اجذ مع أشخاص & & & \\
\hline التو اجد مع كائنات حية & & & \\
\hline اخرى & & & \\
\hline \multicolumn{2}{|c|}{ اللاو اقعية } & & \\
\hline \multicolumn{2}{|c|}{ محاكاة الو اقع الحققيقي } & \multirow[t]{7}{*}{ المحاكاة } & \\
\hline 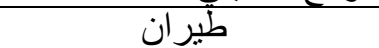 & \multirow{3}{*}{ محاكاة السلوك } & & \\
\hline مشي & & & \\
\hline رؤية & & & \\
\hline كائنات & \multirow{2}{*}{ محاكاة الحجوم } & & \\
\hline الشياء & & & \\
\hline \multicolumn{2}{|c|}{ محاكاة للافعال/ مباشرة } & & \\
\hline \multicolumn{2}{|c|}{ عو الم مصطنعة } & \multirow[t]{2}{*}{ الاصطناعية } & \\
\hline \multicolumn{2}{|c|}{ عو الم مبدعة } & & \\
\hline \multicolumn{2}{|c|}{ استجابات لنافعال } & \multirow[t]{2}{*}{ الفعالية } & \\
\hline \multicolumn{2}{|c|}{ عدم الاستحابة للأفعال } & & \\
\hline
\end{tabular}

2-5 الابعادالخاصة بالجوانب النفعية:

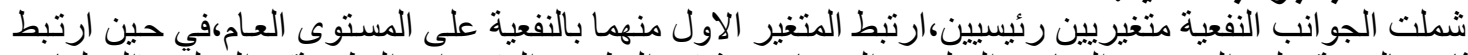

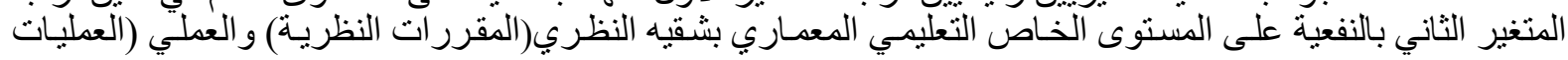


التصميمية)،وهو المستوى الذي تحاول الورقة البحثية تسليط الضوء عليه وتغطيته بشكل مركز ،نظر اللاهمية المنوخاة من

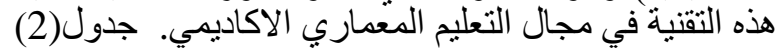

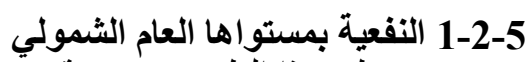

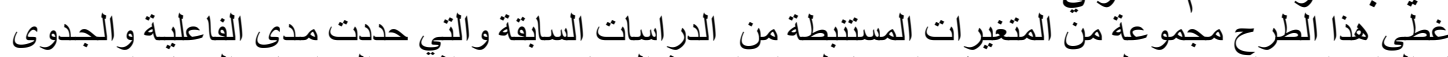

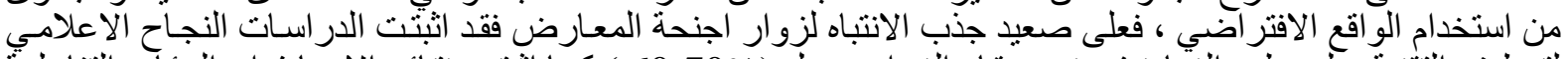

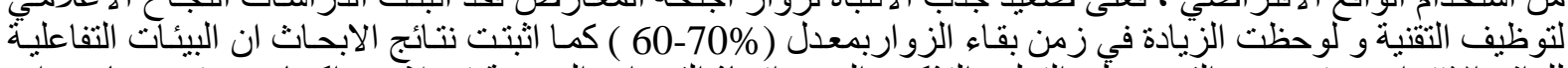

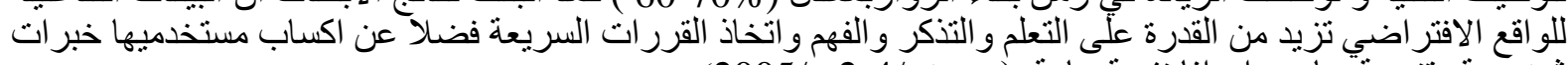

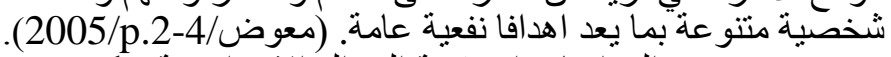

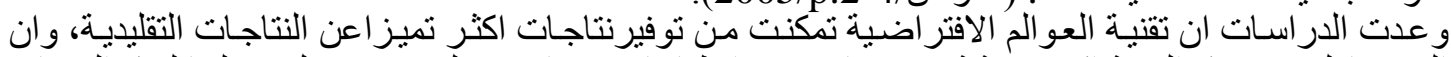

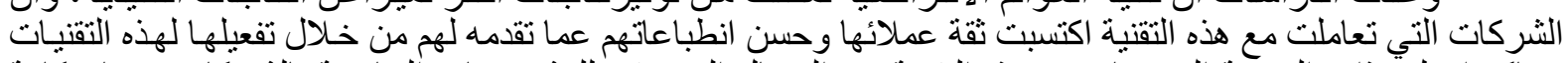

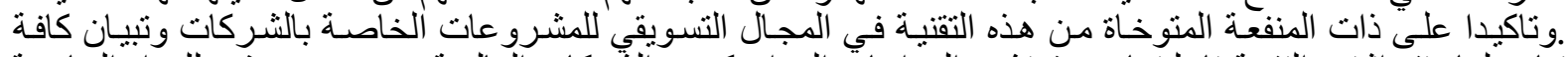

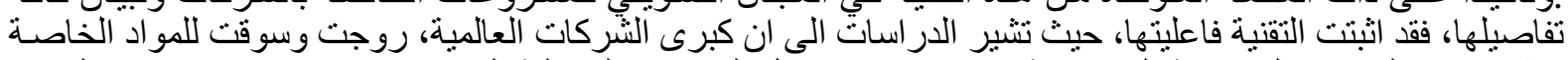

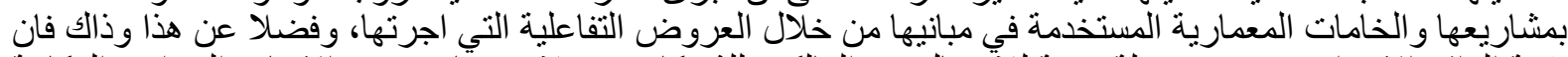

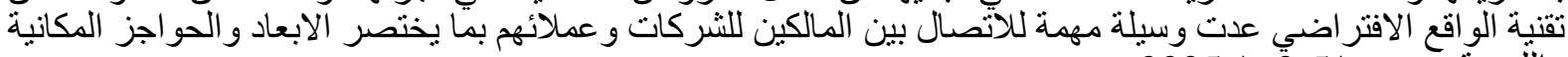

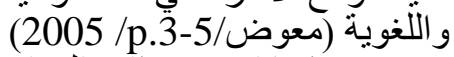

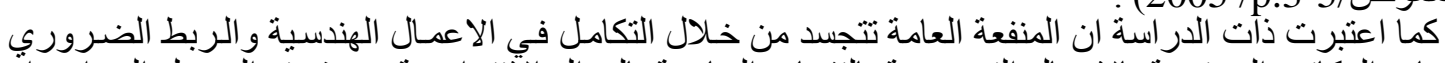

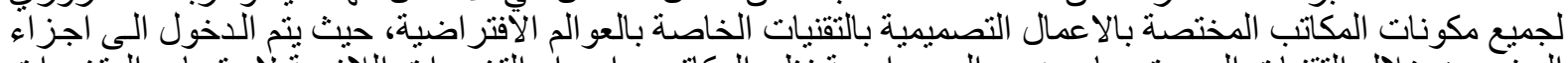

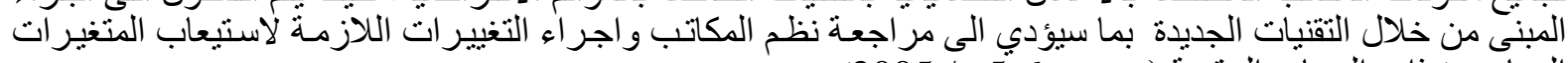

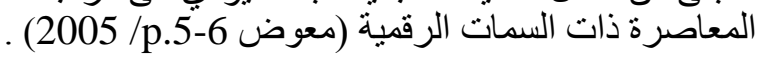

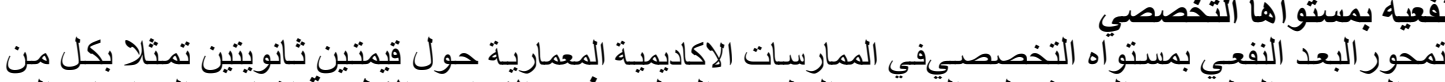

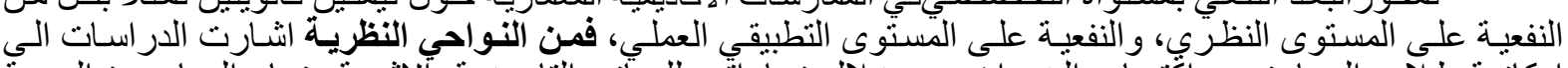

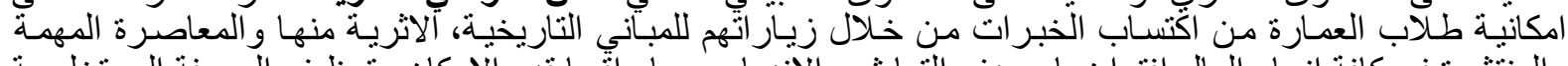

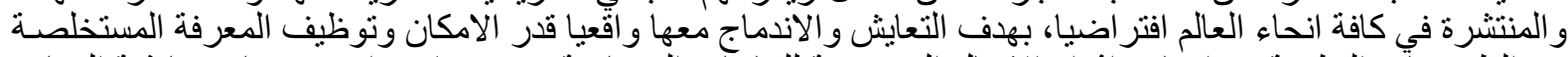

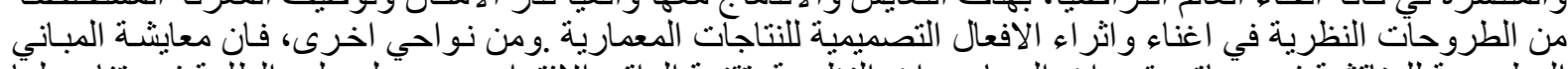

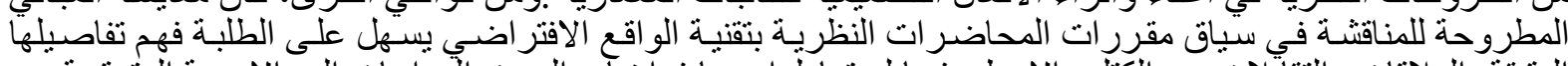

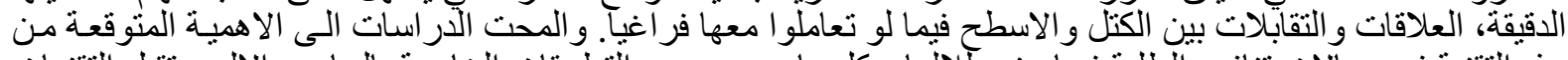

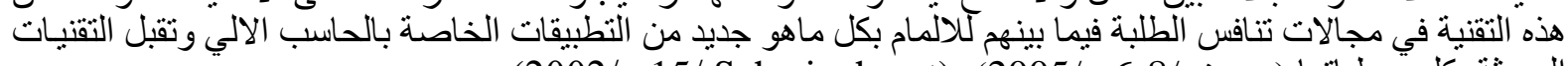

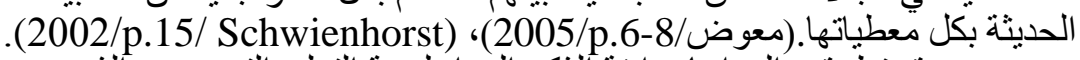

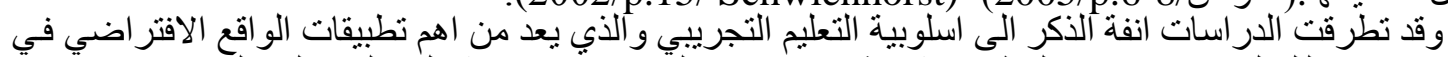

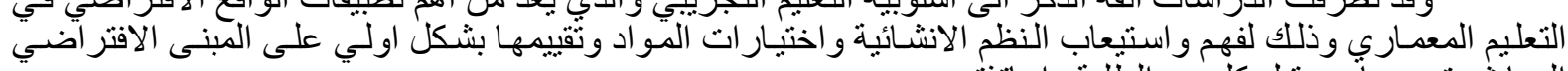

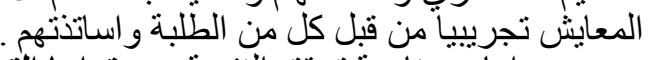

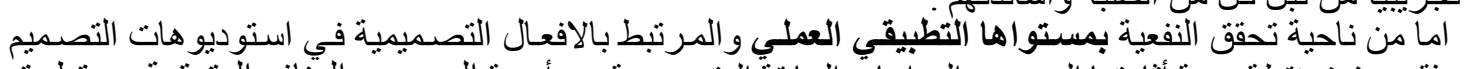

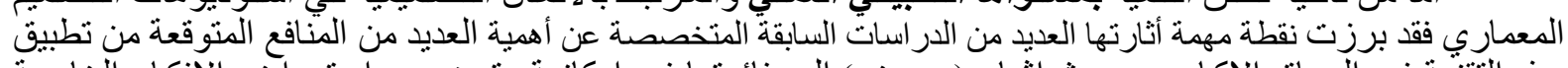

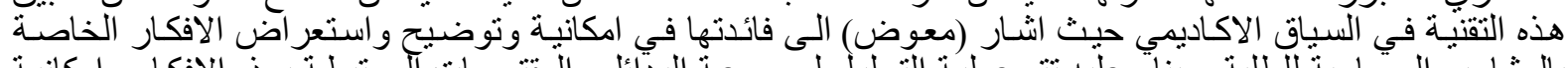

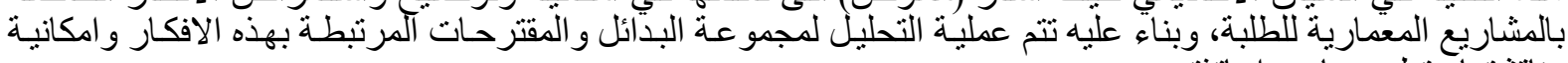

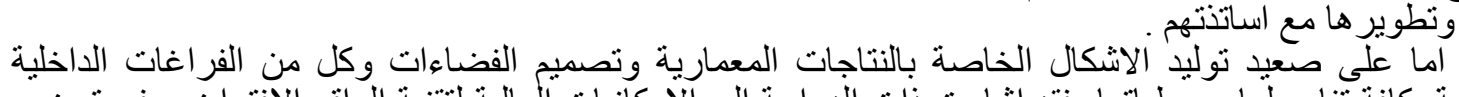

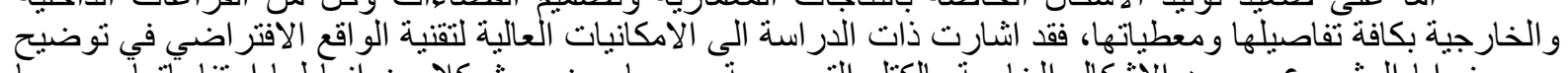

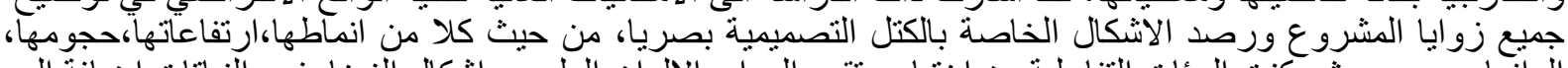

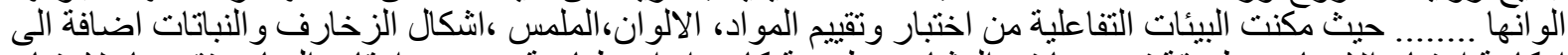

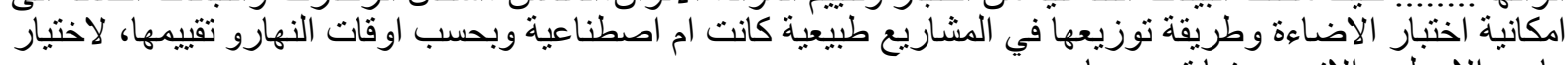

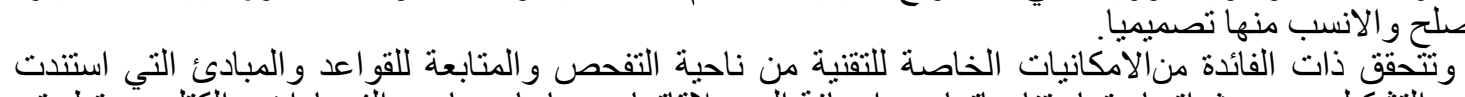

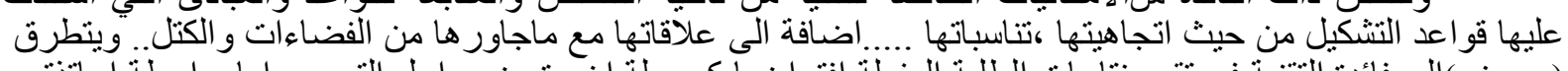

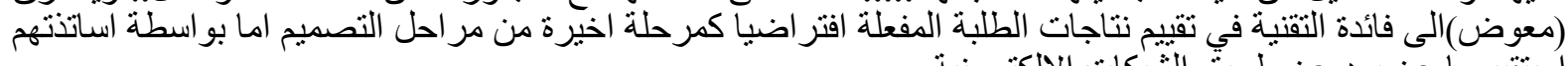

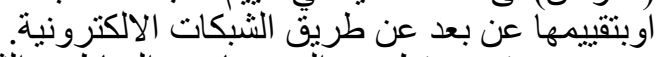

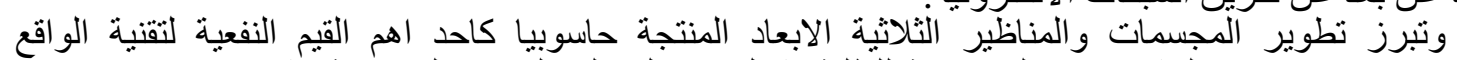

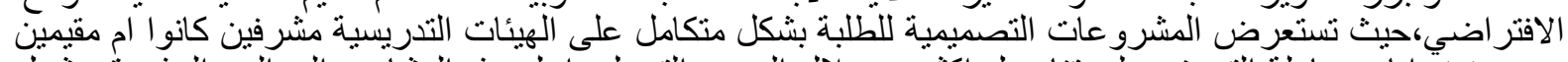

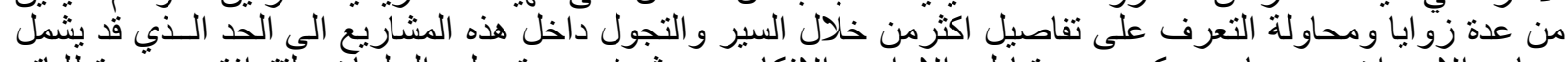

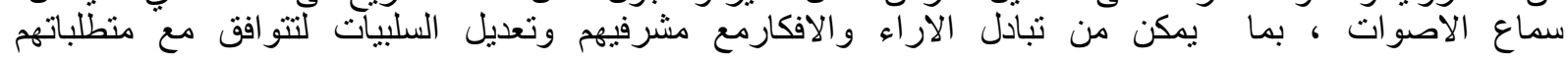




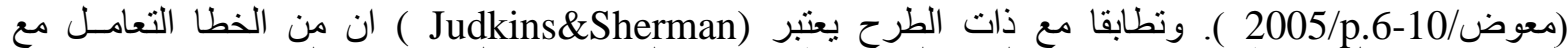

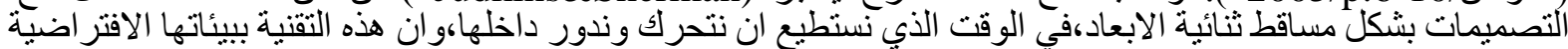

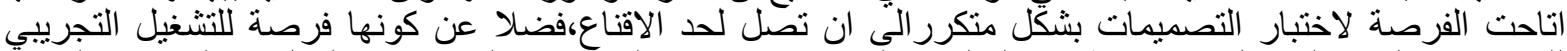

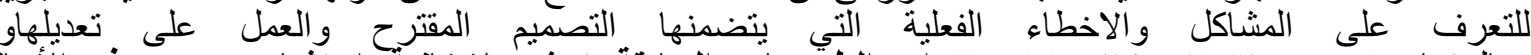

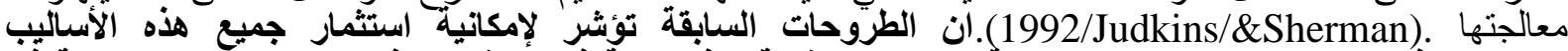

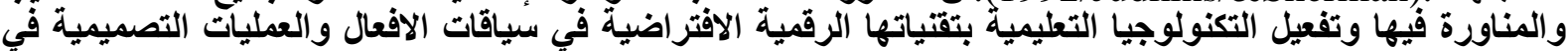

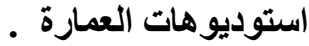

(جدول 2) القيم الممكنة للمتغيرات الخاصة بالجوانب النفعية

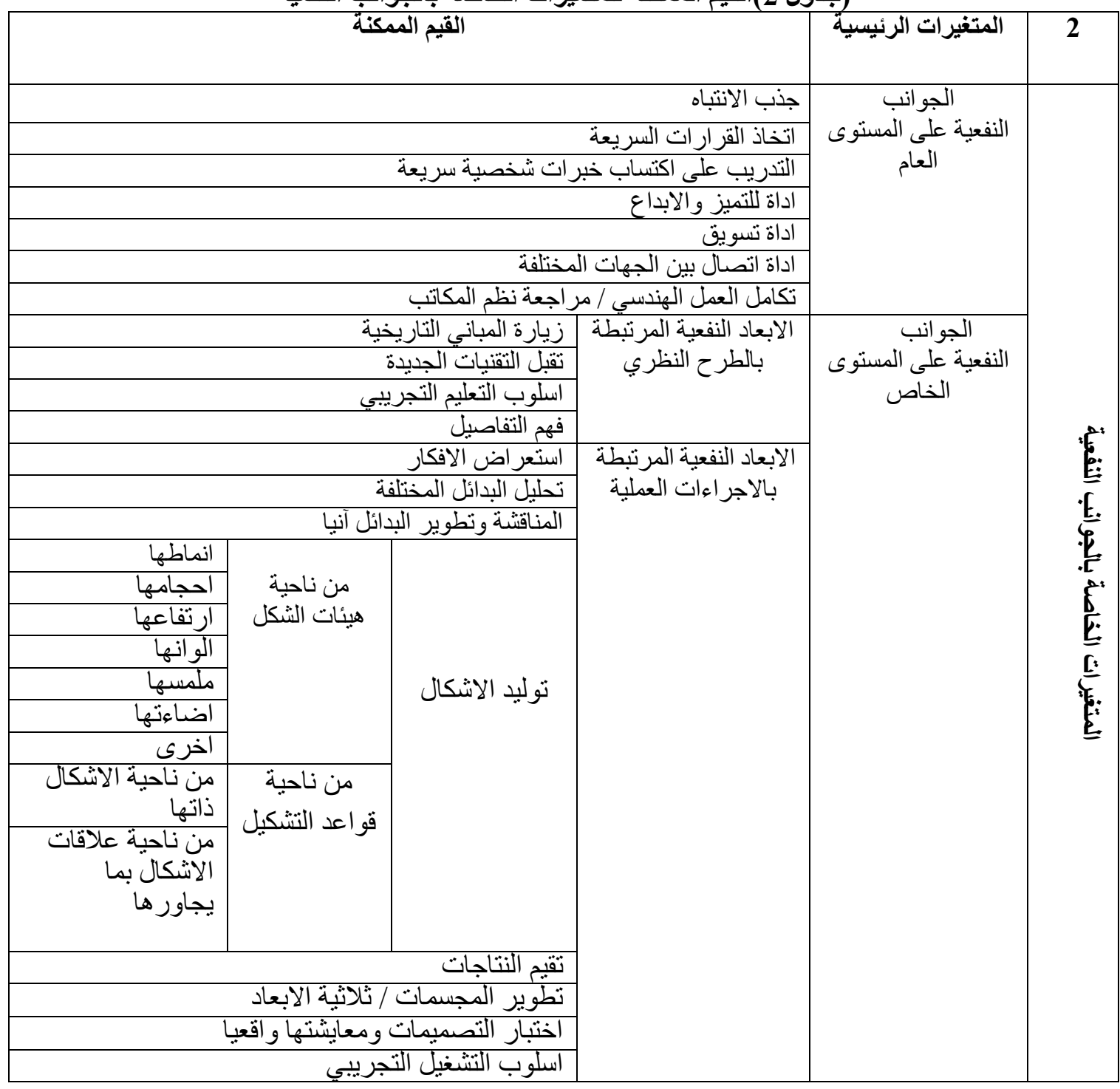

3-5 الابعادالخاصة بالجوانب التقنية:

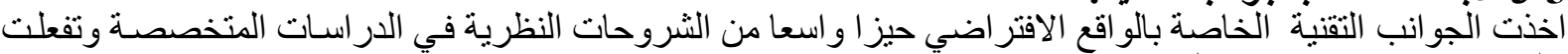

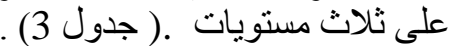

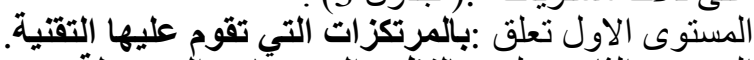

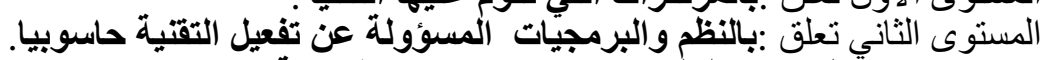

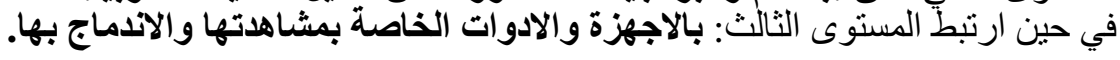


1-3-5 المرتكزات التي تقوم عليها التقنية

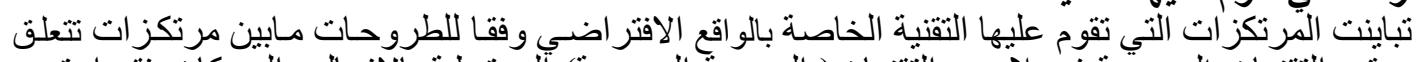

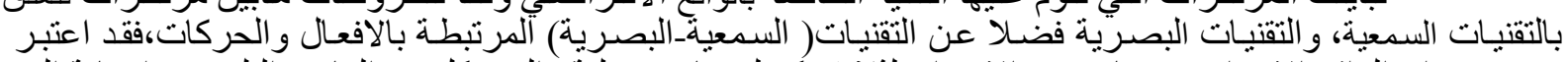

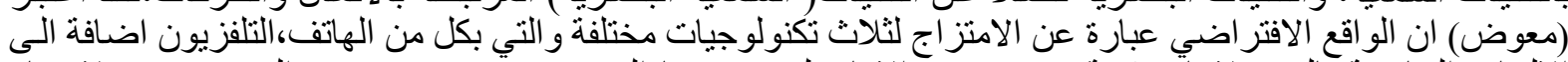

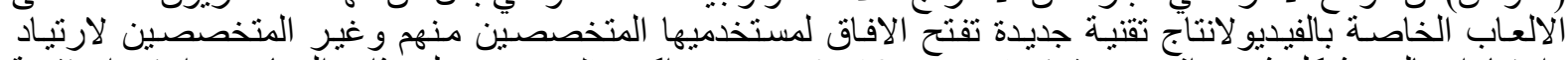

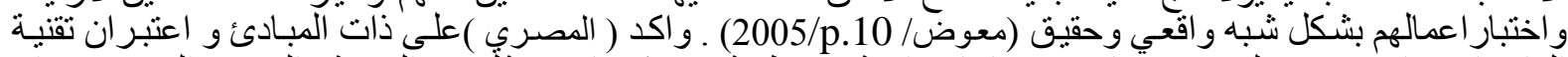

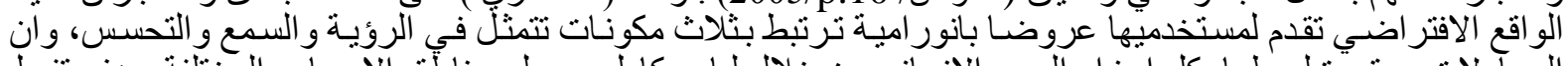

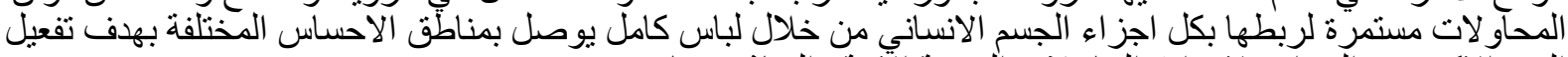

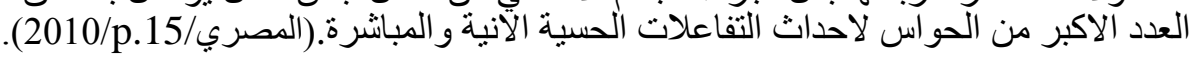

2-3-5 النظم والبرمجيات المسؤولة عن تفعيل التقنية حاسوبيا

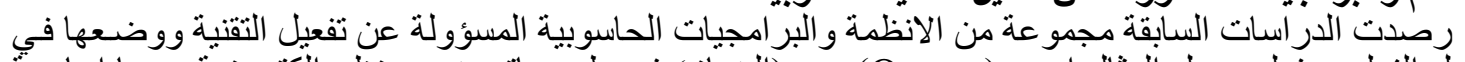

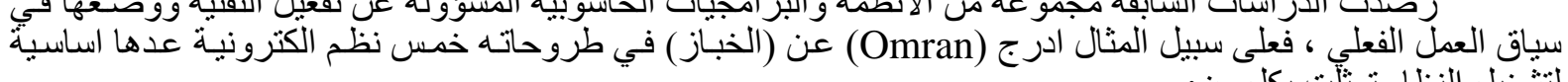

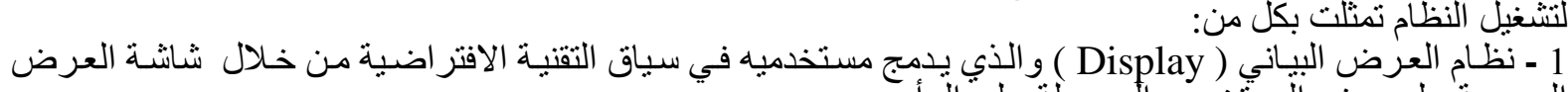

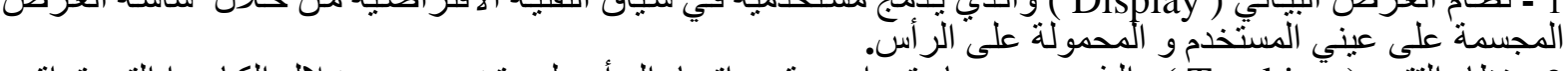

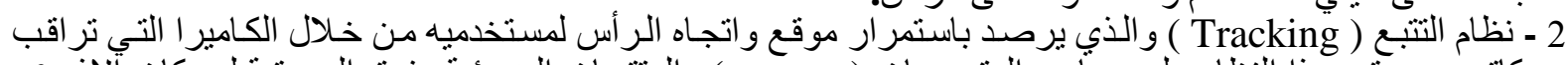

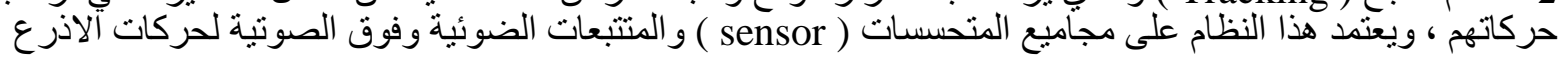

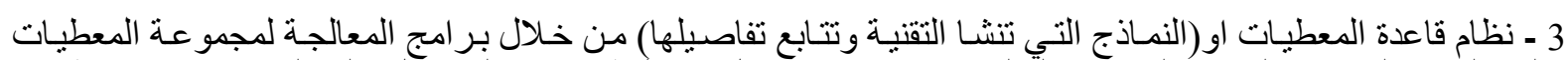

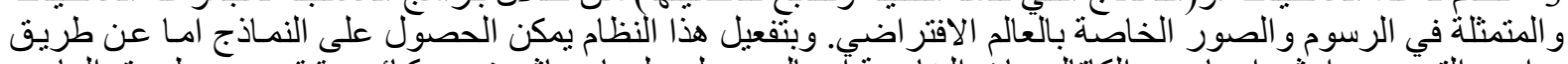

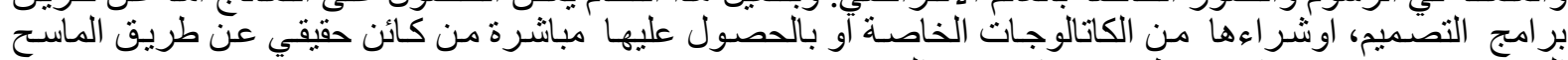

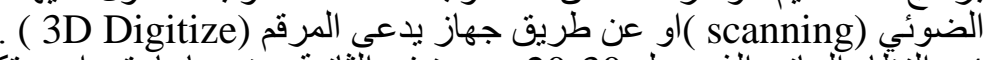

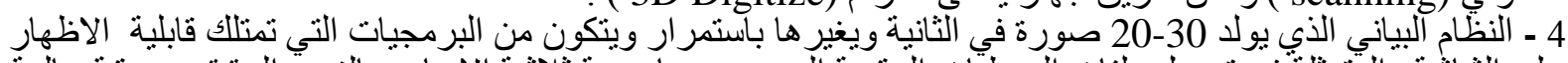

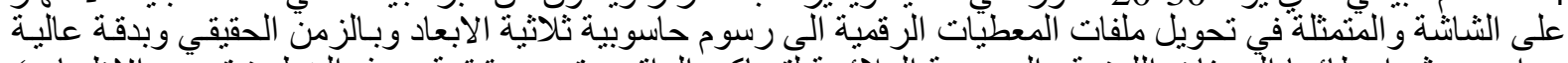

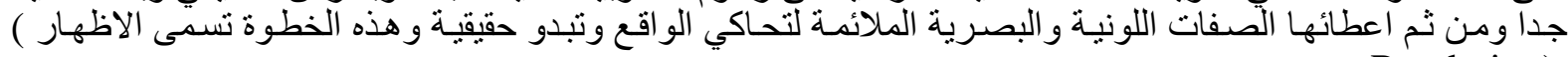
Rendering)

5- نظام المؤثرلت الصوتية بكل معطياتها (2007/P.22/ Omran).

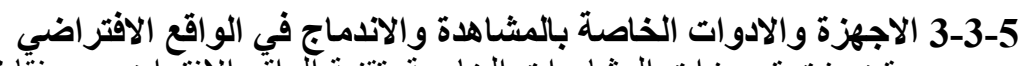

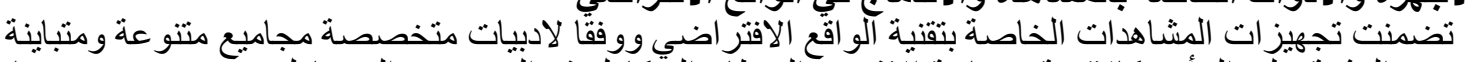

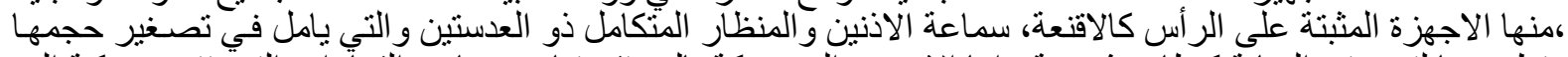

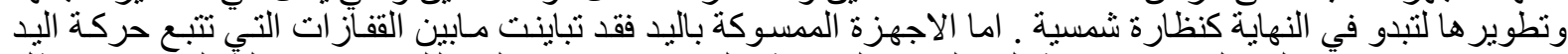

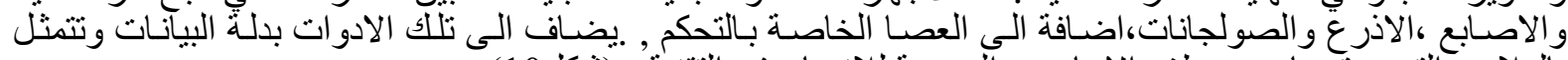

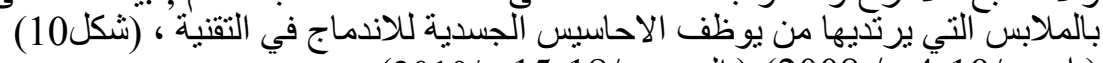

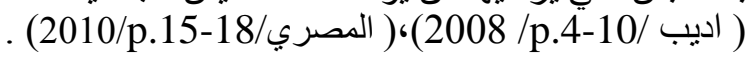
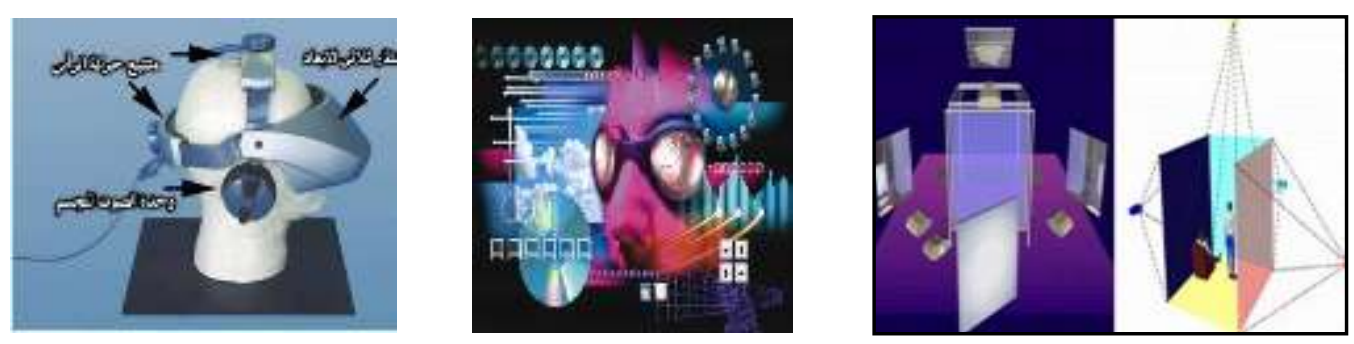

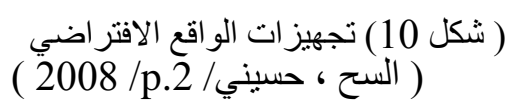

كما وتطرقت الدر اسات الى مايسمى بجهاز الكهف الذي بزود مستخدميه باللقطات من خلال الاسقاطات الهندسية

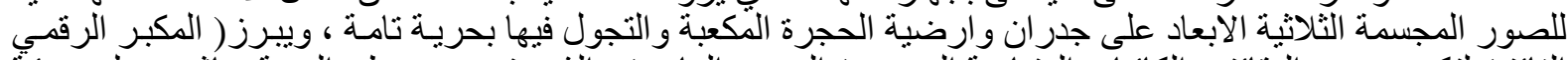

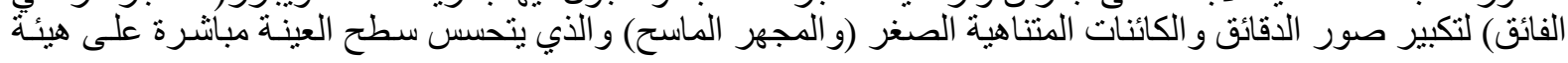


صورة مجسمة ثلاثية الابعاد يمكن تكبير ها الى احجام مختلفة واحدا من اهم التجهيز ات الموظفة في تفعيل هذه التقنيـة(شكل

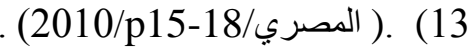

ان جميع ماورد اعلاه يؤشر للاهمية المتحققة من تفعيل التقتيات التي يستتد اليها الواقع الافتراضسي وتوظيف

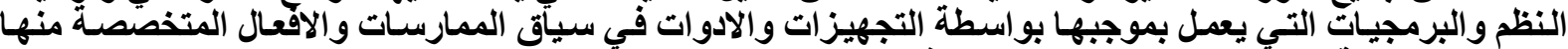

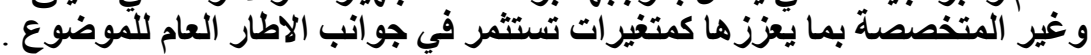

رات (جدول3) القيم الممكنة للمتغيرات الخاصة بالجوانب التقنية

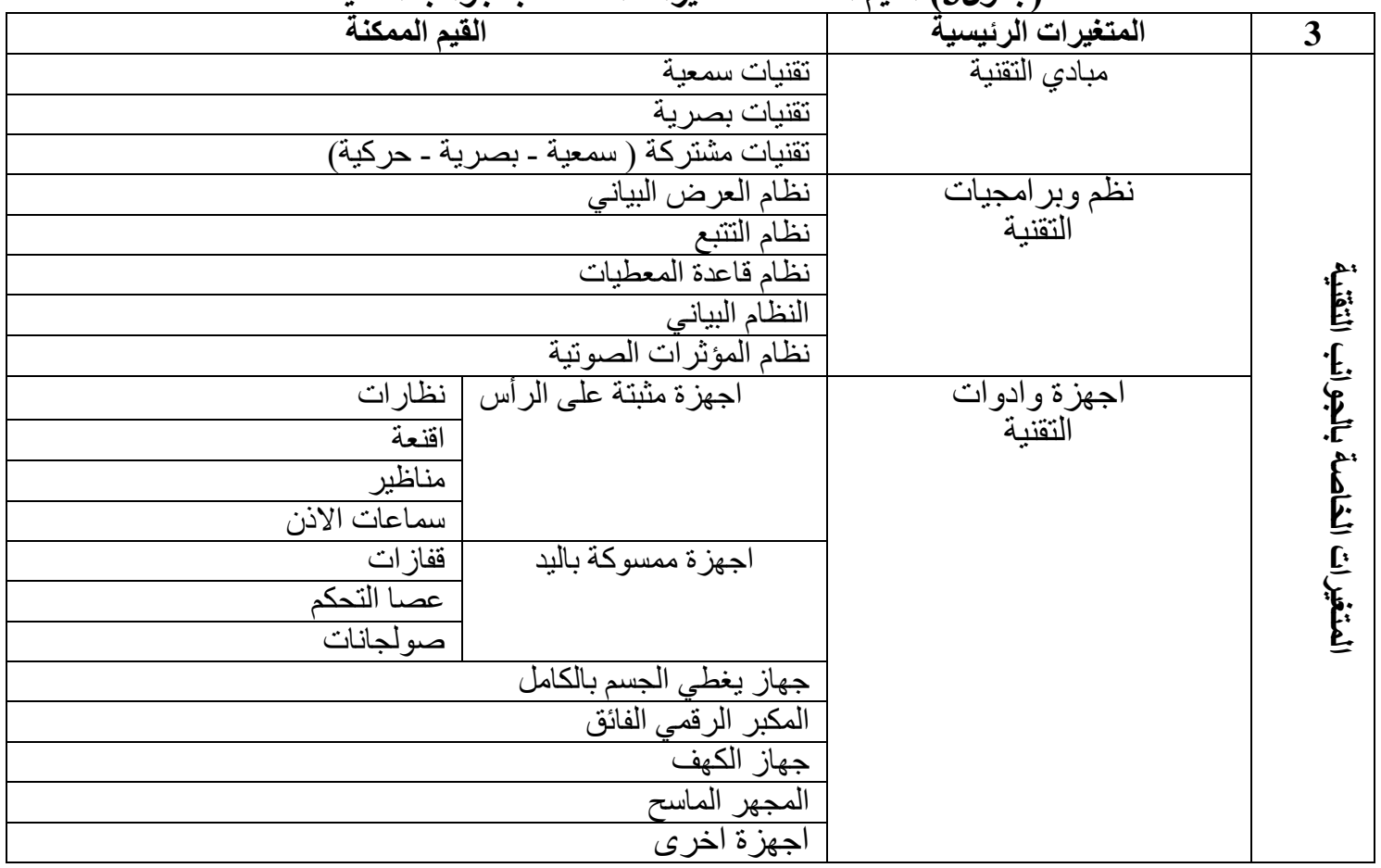

6- 6 التطبيق ومستلزماته

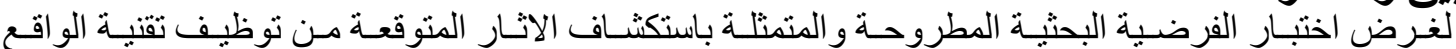

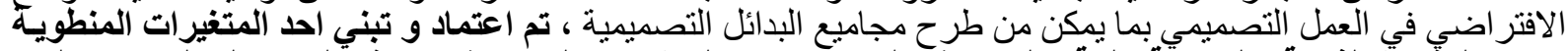

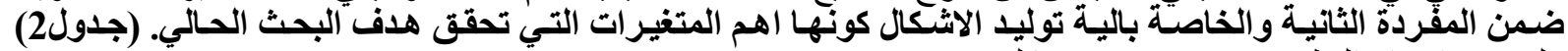
ولغرض اجر اء التطبيق ،لابد من تحديد مايلي: ـ ـ النمط الخاص بالبيئة الافتر اضية قيد التجربة ـ تصميم نموذج البحث بالبئ

1-6 النمط الخاص بالبيئة الافتراضية قيد التجربة

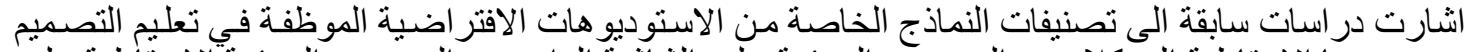

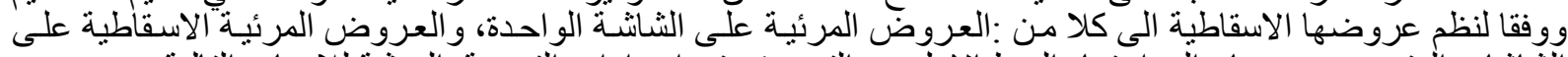

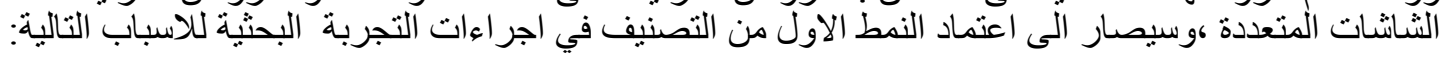

أـ كونه يوفر اقل درجة من الانغماس و التفاعل المادي و اعلى درجات التفاعل المنطقي و العلمي.

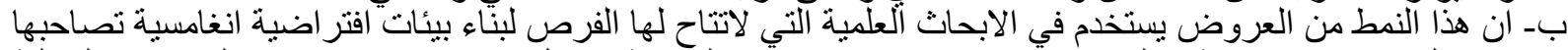
ردود افعال وتغذيات راجعة ، لتعذر وجود الاجهزة والادوآت الخاصة بتفعيل استخدامها في سياق الجامعات المحلية

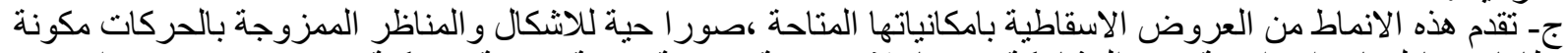

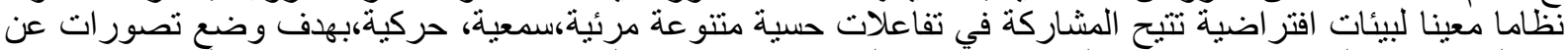

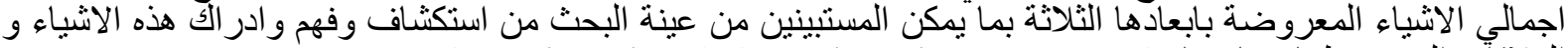

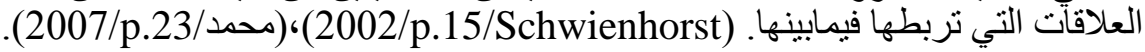


بــ البر امج الحاسوبية المعتمدة

د- نمط الاختبار
2-6 تصميم نموذج البحث

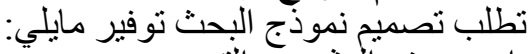

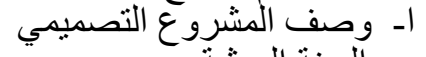

ج - العينة البحثية

ه- الاعداد و التهيئة للعرضئة التحن

يعد المشروع التصميمي قبد التطبيق،احد المشاريع الحضرية الاكاديمية المقدمة من قبل طلبة المرحلة الخامسة

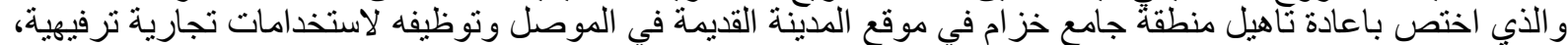

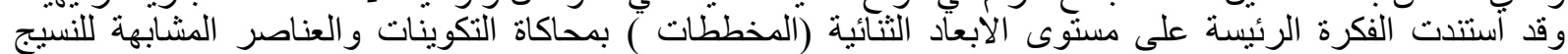

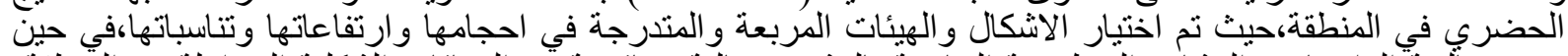

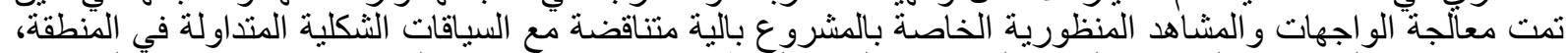

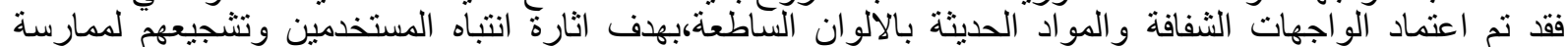

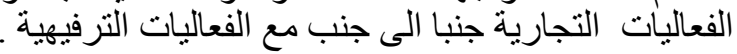
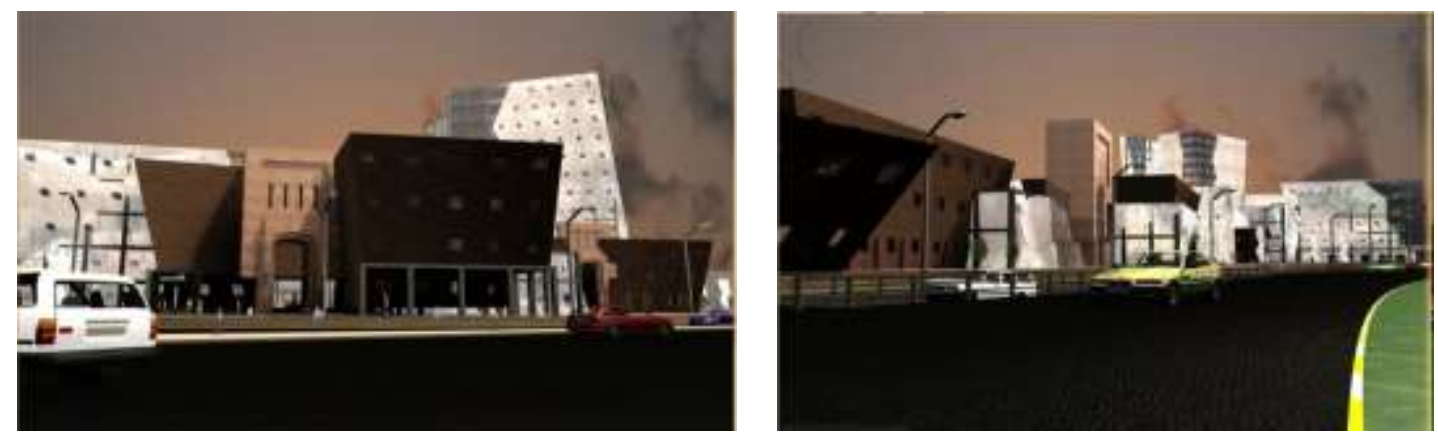

(شكل 11) لقطات من المشروع التصميمي قيد التطبيق

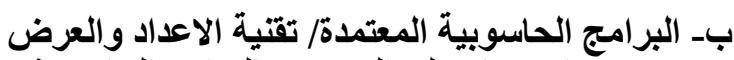

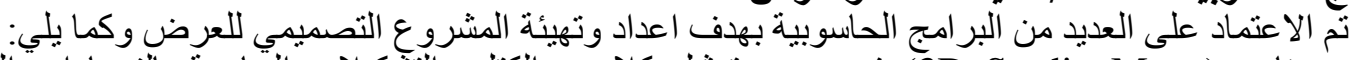

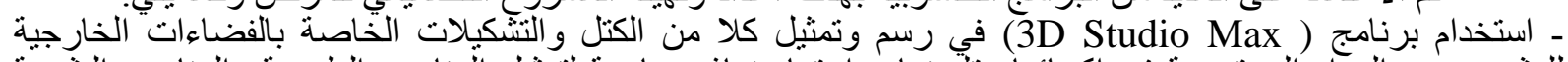

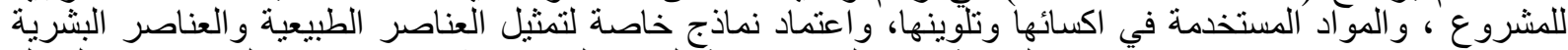

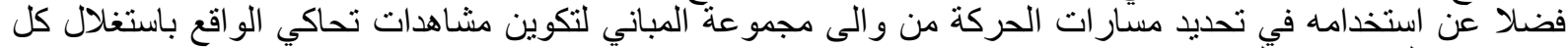
الامكانيات التي يتيحها آلبرنامج تصن.

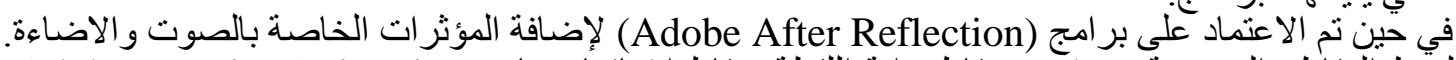

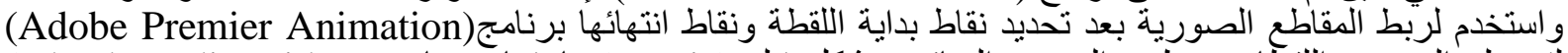

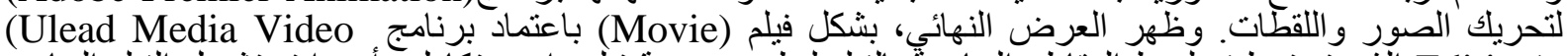
Edition)

بالمشروع التصميمي من خلال برنامج (Real Player).

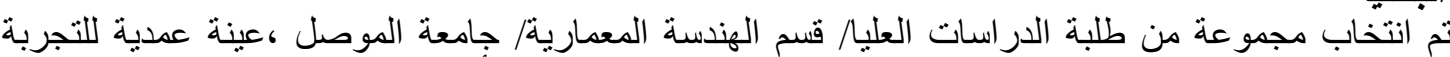

ج- العينة البحثية

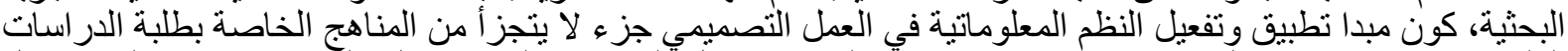

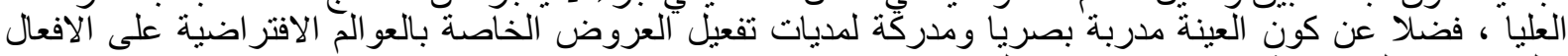
و الممارسات التصميمية بما يحقق اغر اض اضلبن البحث.

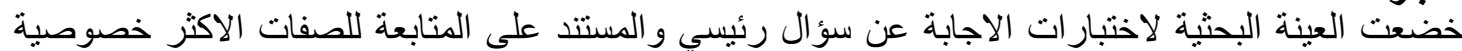

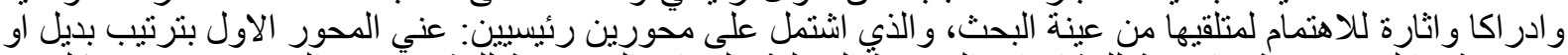

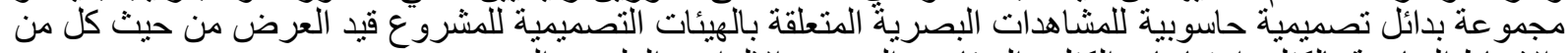

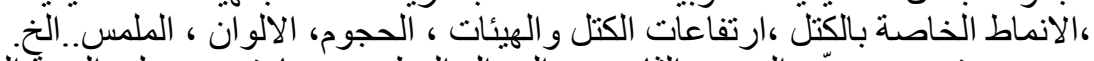

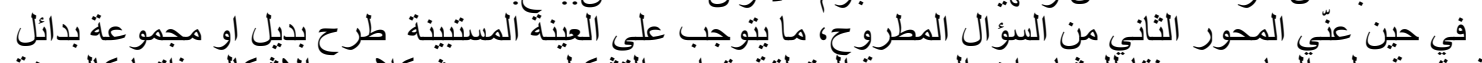

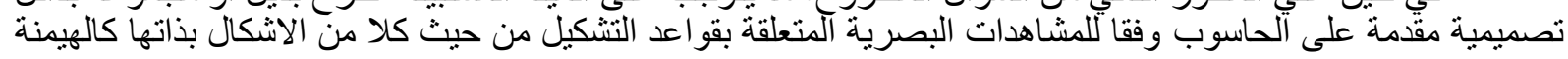


، الاتجاهية، النسب و التناسب .....اضافة الى تثبيت مجمو عة البدائل عن العلاقات الخاصة بالاشكال التصميمية بما يجاور ها من الفضاءات كعلاقات كل من التجاور، التداخل او الاحتواء.

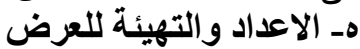

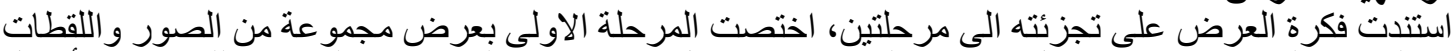

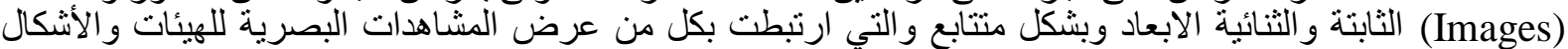

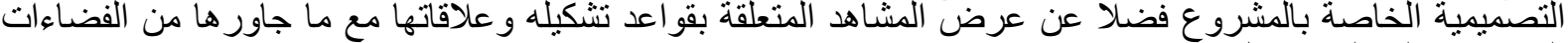

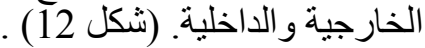
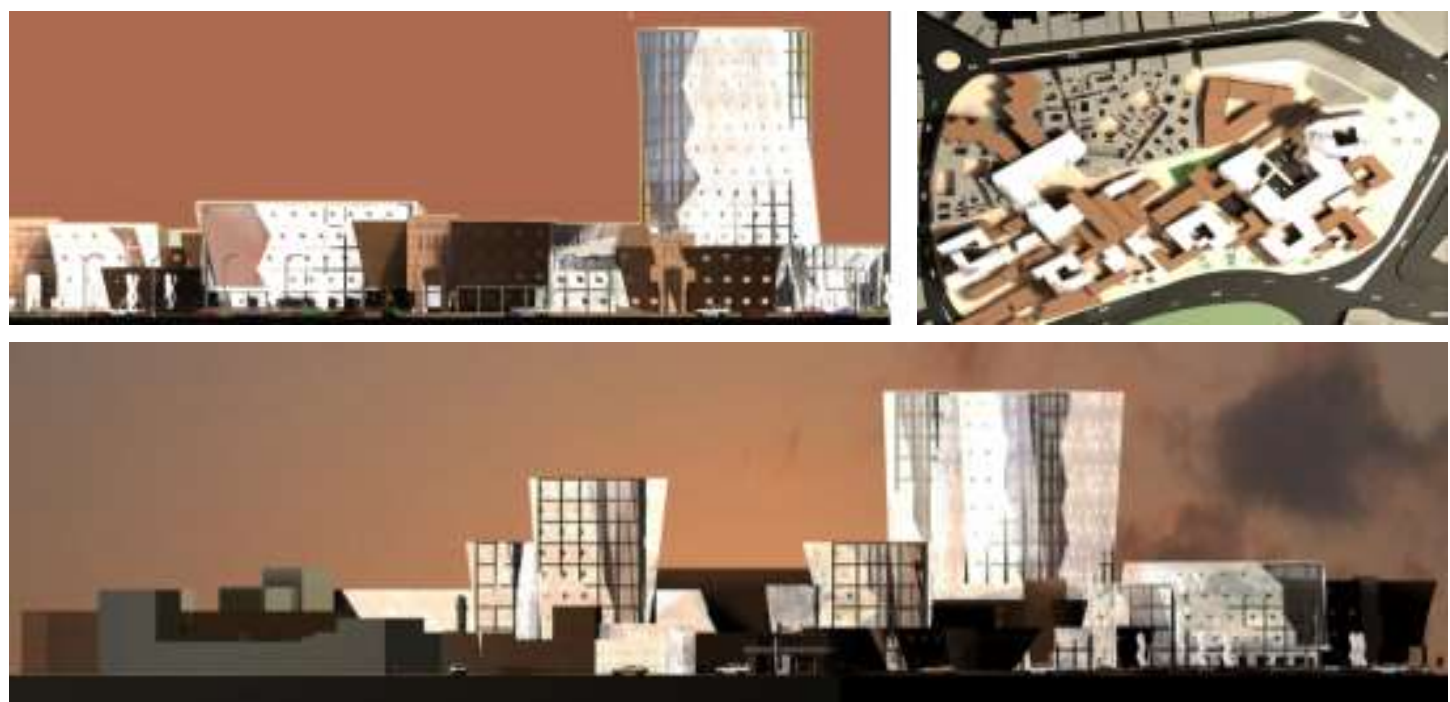

(شكل 12) مجمو عة من الصور و اللقطات الثابتة و الثنائية الابعاد

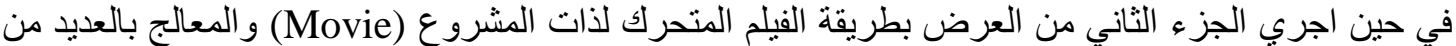

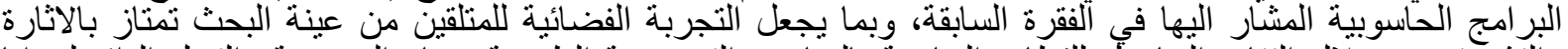

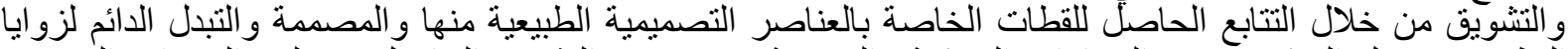

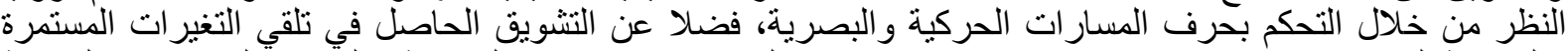

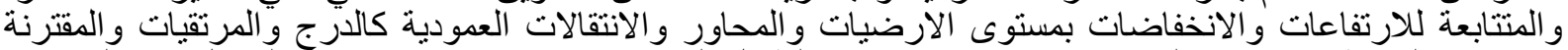

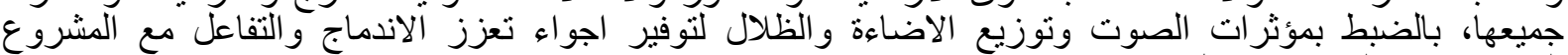

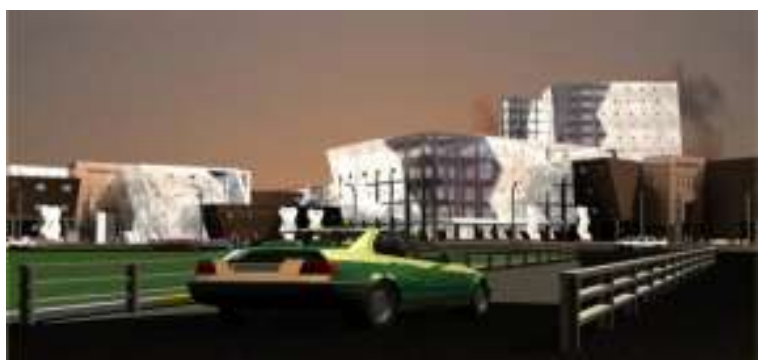

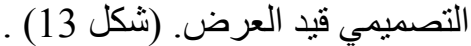
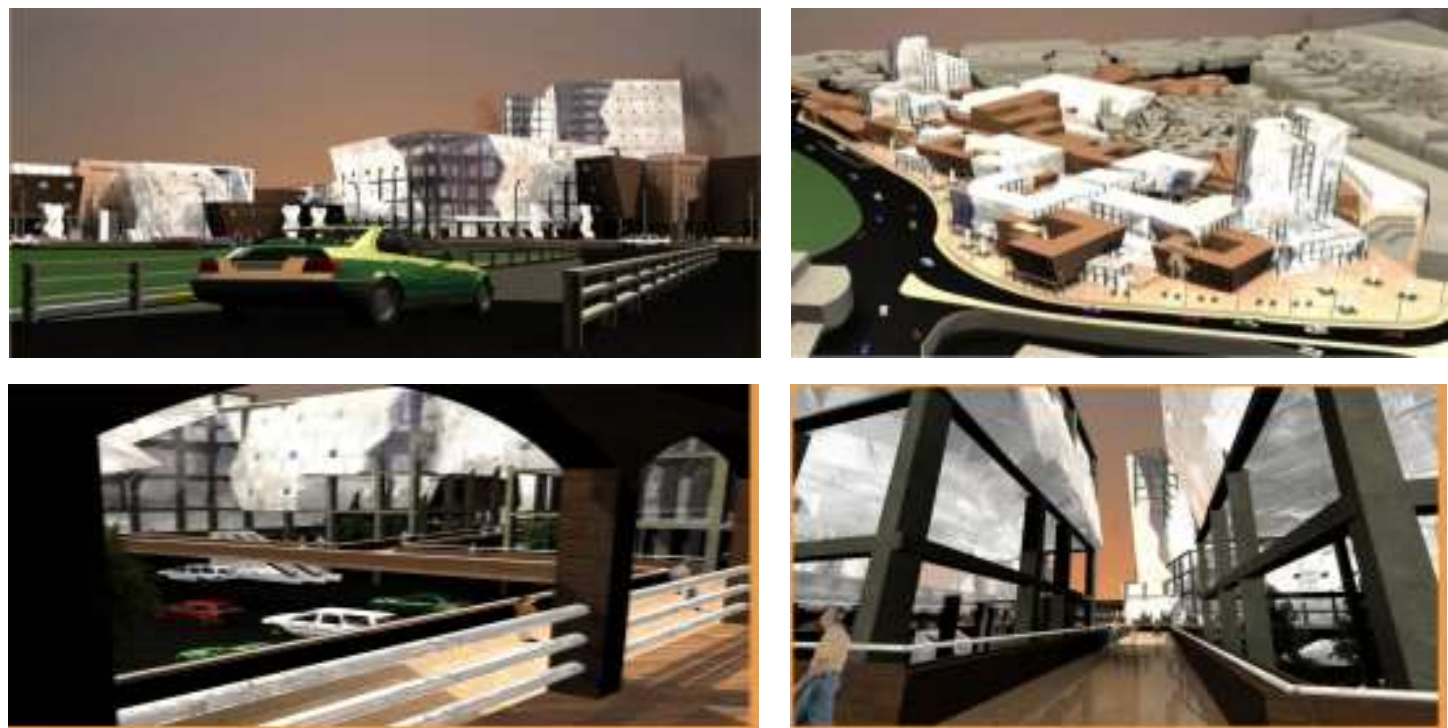

$$
\text { (شكل 13) مجمو عة من الصور توضح اللقطات المتحركة }
$$


3-6 نتائج التجربة البحثية

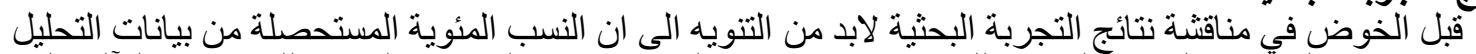

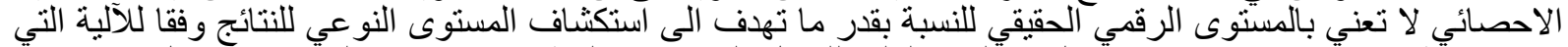

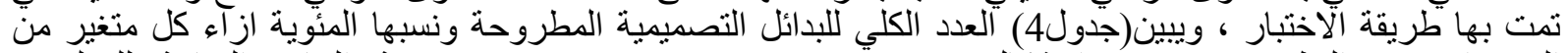

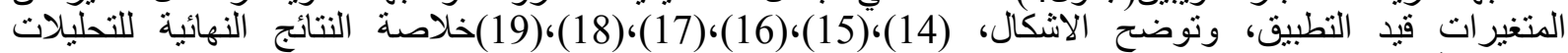
الاحصنيائية.

جدول (4) خلاصة نتائج النسب المئوية للبدائل التصميمية الخاصة بالتجربة البحثية

\begin{tabular}{|c|c|c|c|c|c|c|c|}
\hline اللبائوية & المطروحة البدل & اللبائوية & المظروحة & \multirow{2}{*}{\multicolumn{2}{|c|}{ القيم الممكنة }} & الرئيسيرات & \\
\hline \multicolumn{2}{|c|}{ (لقطات متحركة) } & \multicolumn{2}{|c|}{ (لقطات ثُابتَة) } & & & & \\
\hline$\% 10$ & 7 & $\% 10$ & 5 & \multicolumn{2}{|c|}{ الاشكال } & الكتل و الهيئات & \\
\hline$\% 13$ & 9 & $\% 6$ & 3 & \multicolumn{2}{|c|}{ الحجوم } & & $\hat{n}^{2}$ \\
\hline$\% 9$ & 6 & $\% 11$ & 6 & \multicolumn{2}{|c|}{ الارتفاعات } & التصميمية & $\tilde{\xi}$ \\
\hline$\% 6$ & 4 & $\% 17$ & 9 & \multicolumn{2}{|c|}{ الالوان } & & $\underline{E^{*}}$ \\
\hline$\% 3$ & 2 & $\% 14$ & 7 & \multicolumn{2}{|c|}{ الملمس } & & 6 \\
\hline$\% 2$ & 1 & $\% 8$ & 4 & \multicolumn{2}{|c|}{ الاضاءة } & & E: \\
\hline$\% 3$ & 2 & $\% 7$ & 4 & النسبة و التناسب & \multirow{4}{*}{ التصميمية ذاتها } & \multirow{7}{*}{ التشكيل } & E: \\
\hline$\% 5$ & 3 & $\% 8$ & 4 & التوازن & & & E \\
\hline$\% 9$ & 6 & $\% 4$ & 2 & الهيمنة & & & . \\
\hline$\% 11$ & 7 & $\% 2$ & 1 & الاتجاهية & & & $E$ \\
\hline$\% 4$ & 3 & $\% 6$ & 3 & علاقة التجاور & \multirow{3}{*}{ علاقاتها مع } & & $\frac{E}{E}$ \\
\hline$\% 10$ & 7 & $\% 5$ & 3 & علاقة التداخل & & & $\xi$ \\
\hline$\% 15$ & 10 & $\% 2$ & 1 & علاقة الاحتو اء & & & \\
\hline
\end{tabular}

أـ اظهرت النتائج الخاصة بالجزء الأول من العرض الخاص بالمشاهدات البصرية للقطات ثنائية الابعاد ولاجزاء مختلفة

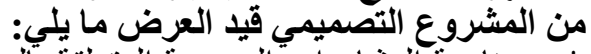

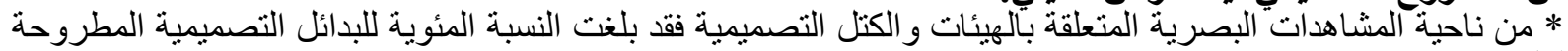

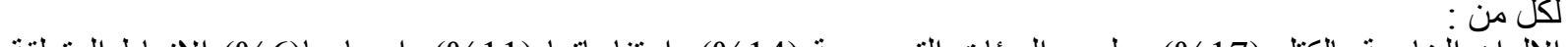
الالو ان الخاصة بالكتل (17\%)، ملمس الهيئات التصميمية (14\%) ،ارتفاعاتها (11\%) )، باحجامها(6\%) الانماط المتعلقة باضاءاتهان(8\%)، واخيرا اشكال الكتل هندسية كانت ام عضوية (10\%).

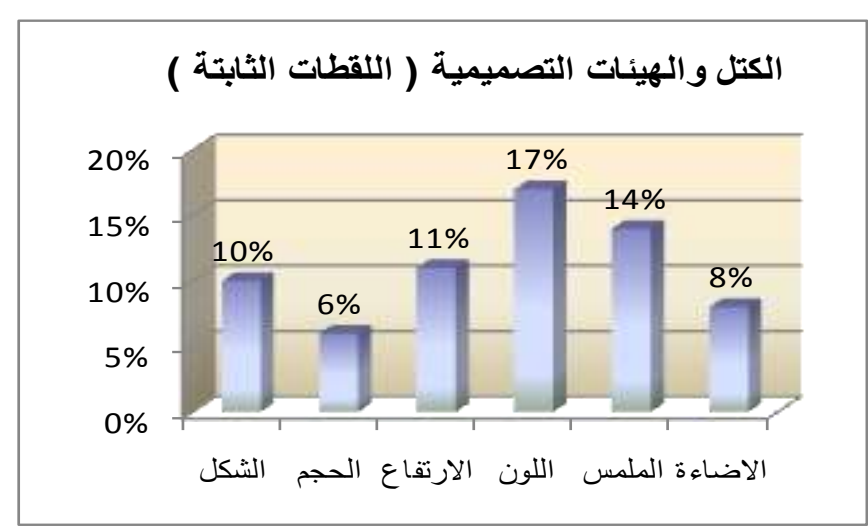

(شكل 14) النسب المئوية للبدائل الخاصة بالكتل و الهيئات التصميمية 
* في حين تمكن المستبينين من اعطاء وتثبيت بدائل تصميمية للمشاهدات البصرية الخاصة بقواعد التشكيل من ناحية

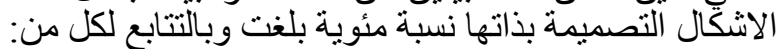

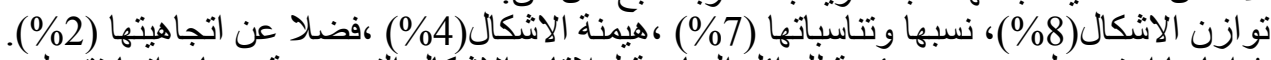

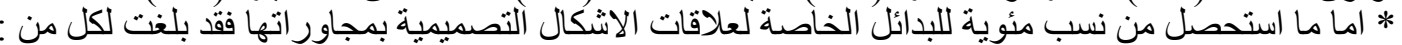
علاقات تداخل الكتل فيما بينها(5\%) ، علاقة التجاور(6\%) ، العلاقات الخاصة بالاحتو ائية (2\%).

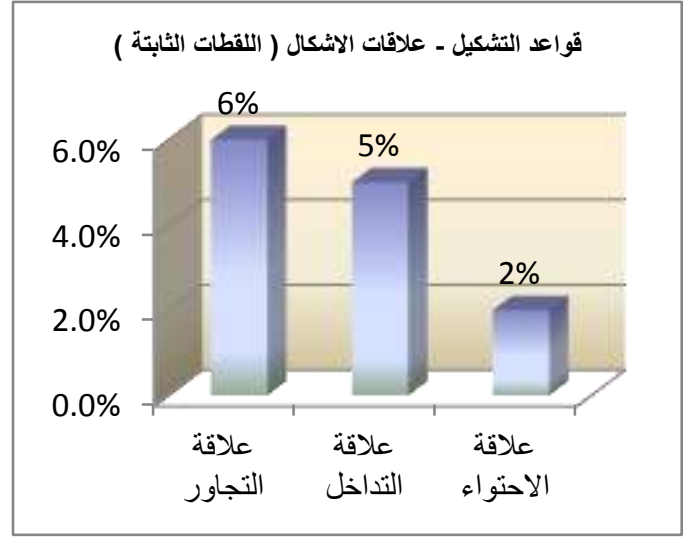

قواعد التشكيل - الاشكال ذاتها (اللقطات الثابتة)

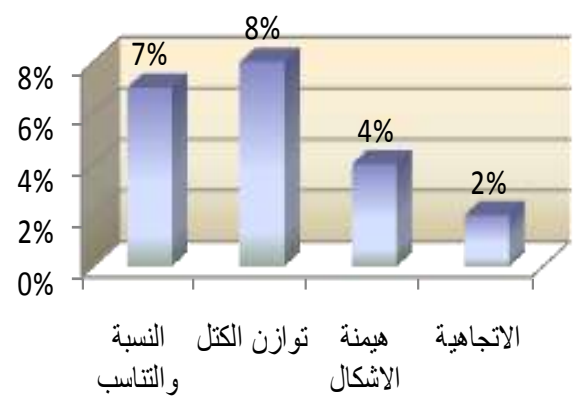

(شكل 15) النسب المئوية للبدائل الخاصة بالاشكال ذاتها (شكل 16) النسب المئوية للبدائل الخاصة بالعلاقات الفضائية بـ اما النتائج المتعلقة بالجزء الثاني من العرض ووفقا بالمشاهدات البصرية المتحركة فقد بلغت النسب المئوية الخاصة باعطاء البدائل التصميمية كما يلئي:

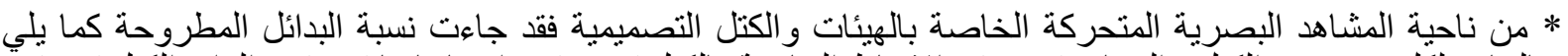

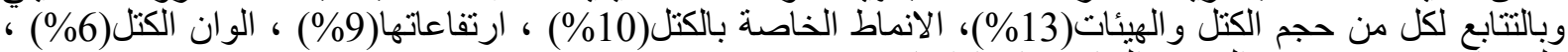

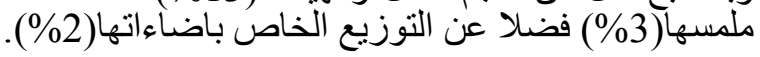

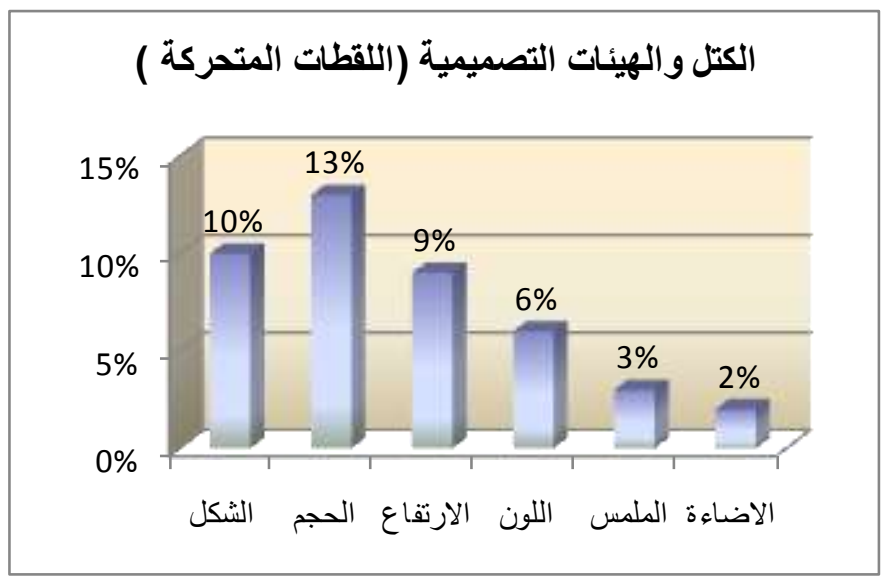

(شكل 17) النسب المئوية للبدائل الخاصة بالكتل و الهيئات التصميمية

* توز عت النسب المئوية للبدائل بناءً على المشاهدات و اللقطات المتحركة فيما يتعلق بقو اعد التشكيل للاشكال بذاتها وكما

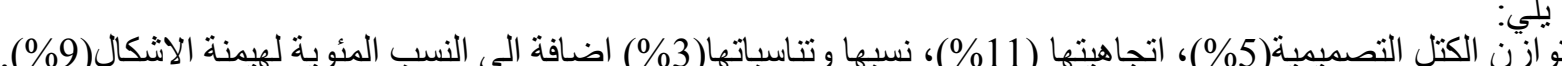

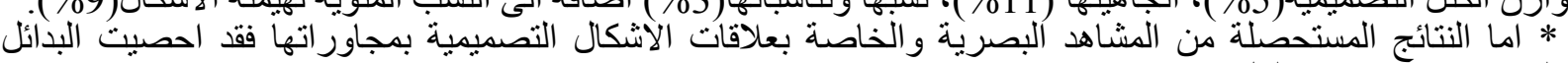
التصميمية تصاعديا ولكل من: علاقات التجاور (4\%)، علاقة التداخل(10\%)، علاقة الاحتو اء(15\%). 

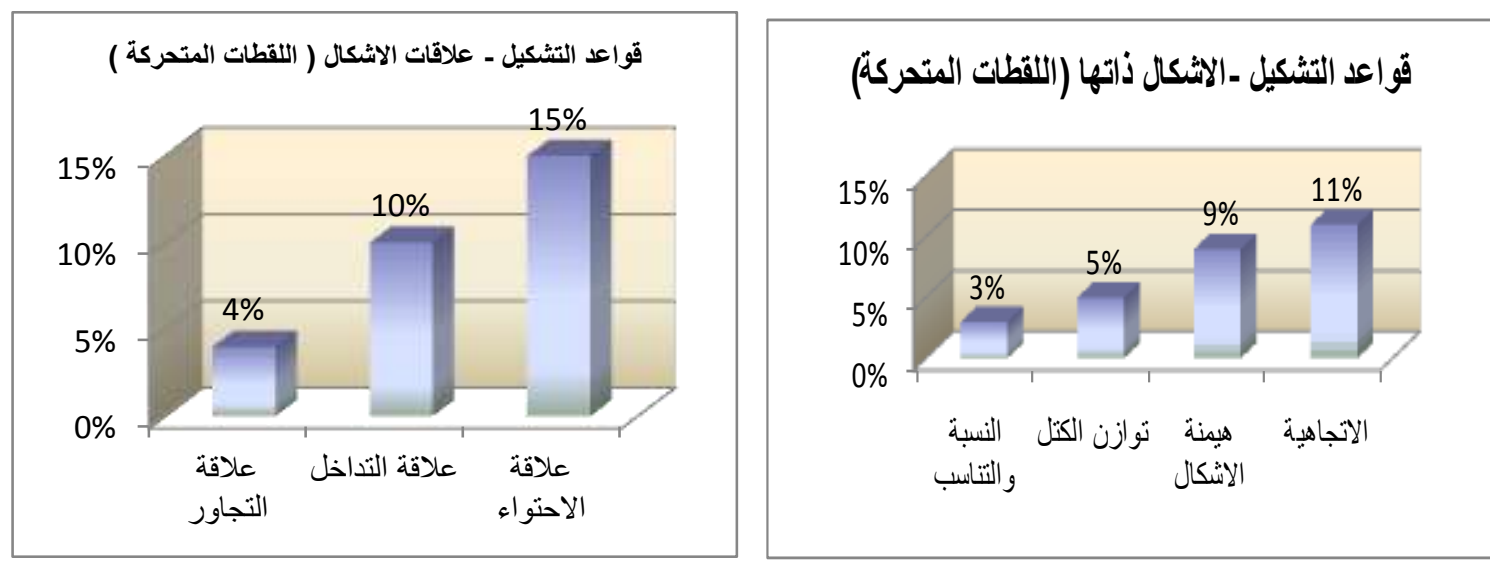

(شكل 18) النسب المئوية للبدائل الخاصة بالاشكال ذاتها (شكل 19) النسب المئوية للبدائل الخاصة بالعلاقات الفضائية

\section{7-الاستنتاجات 1-7 الأستنتاجات الخاصة بالاطار النظري}

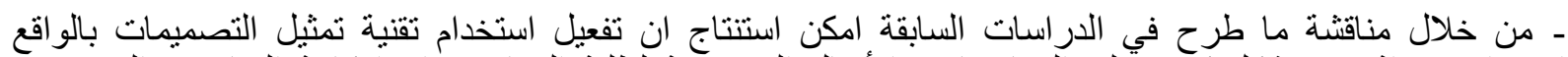

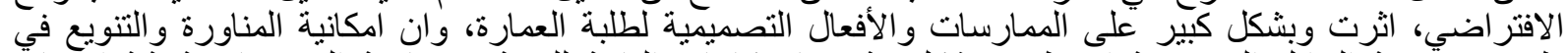

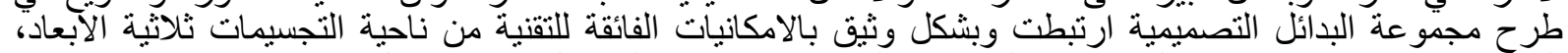

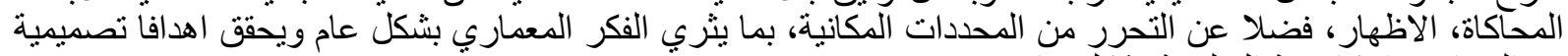

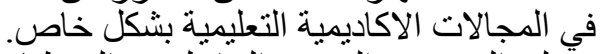

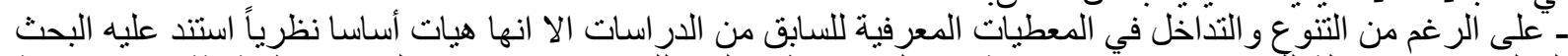

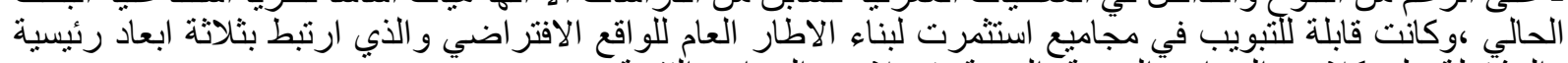

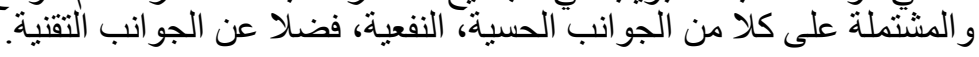

7- 2 الاستنتاجات الخاصة بالدراسة العملية

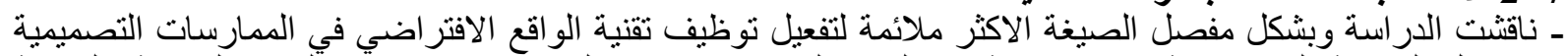

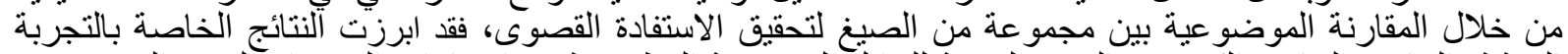

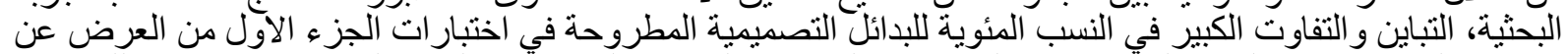

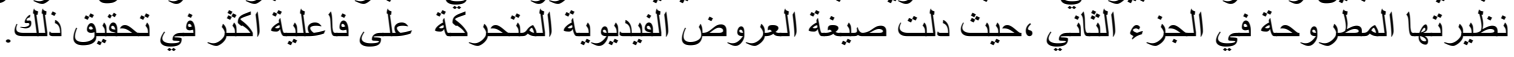

ـ بينت النتائج ان البدائل التصميمية المطروحة بناءً على المشاهدات والعروض البصرية بالقطات والصور الثنائية الابعاد

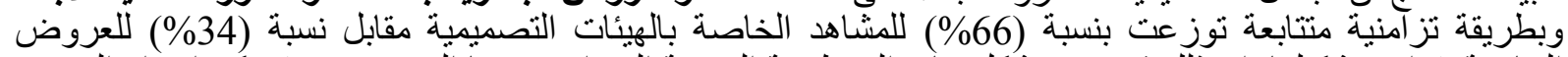

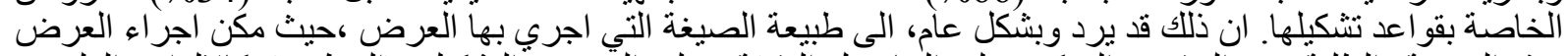

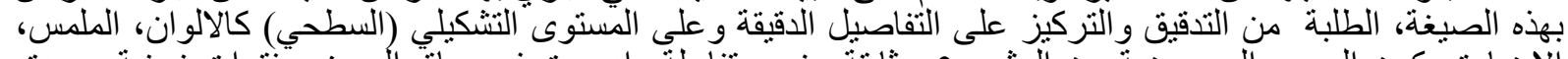

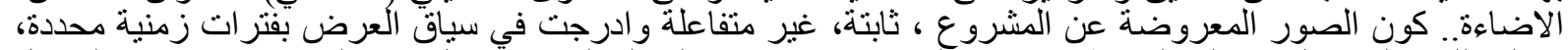

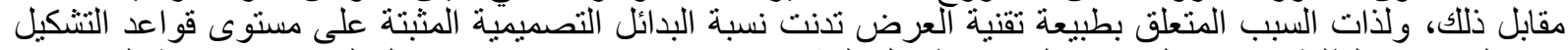

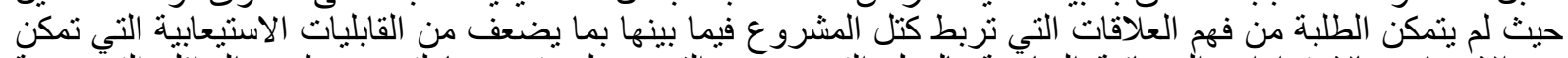

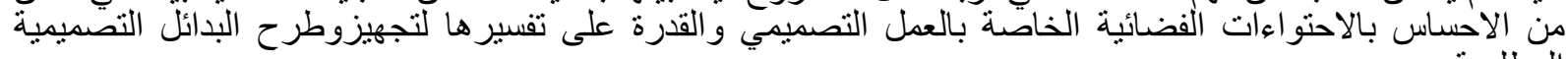
المطلوبة.

- و على المستوى التفصيلي ، تمكن المستبينون من عينة البحث من طرح الحلول التصميمية بنسب مئوية عالية لكتل

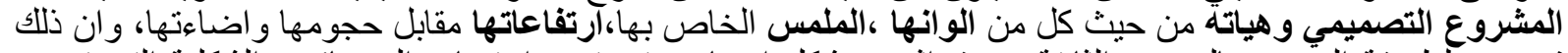

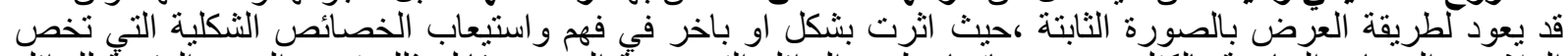

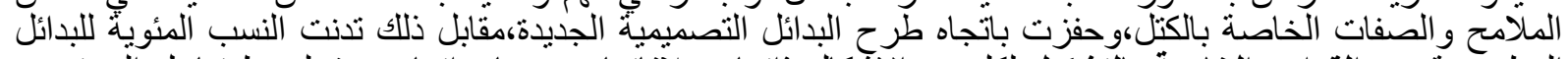

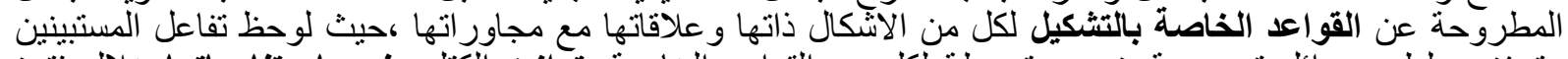

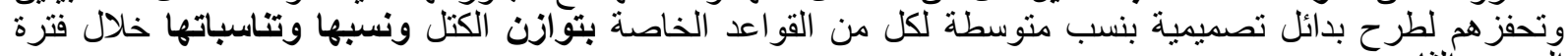

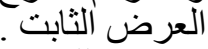

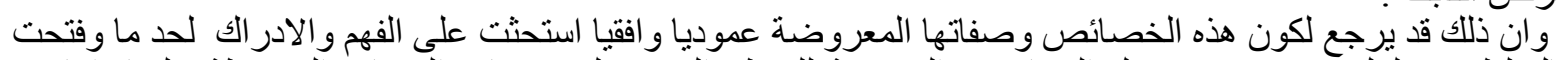

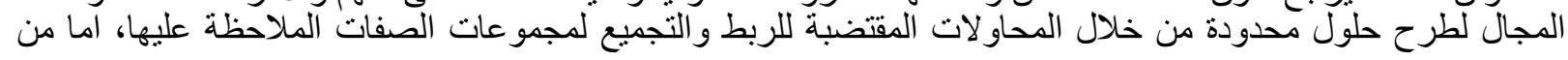


ناحية علاقات الاشكال فقد كانت لعلاقتي التجاورو التداخل وبالتتابع النصيب الاكبر من اثارة الاهتمام وشد الانتباه و التحفيز

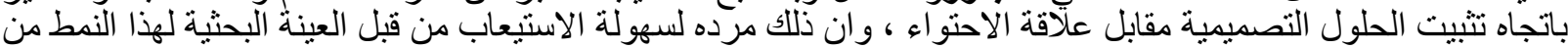

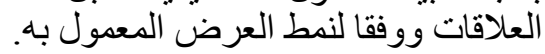

ـ اظهرت الاجر اءات البحثية الخاصة بطرح البدائل التصميمية و المستحصلة من المشاهدات البصرية للتجربة الفضائية

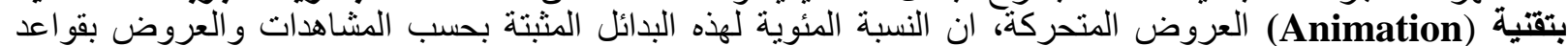

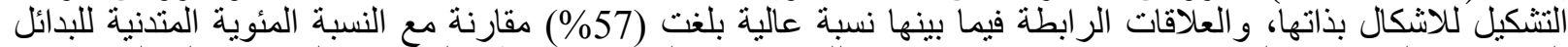

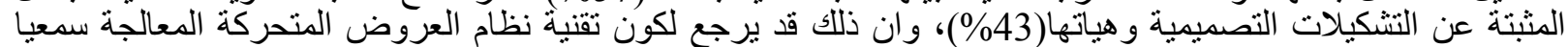

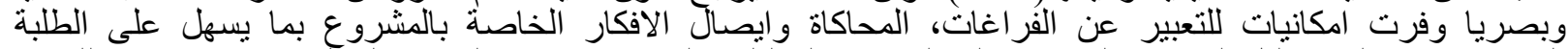

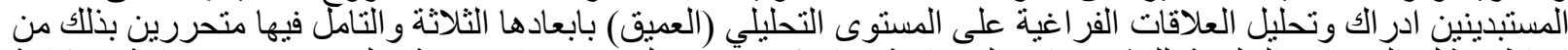

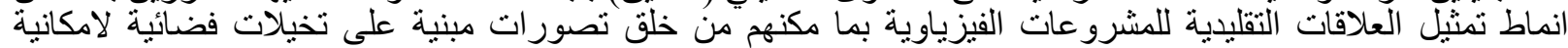
المناورة و التحوير واعادة صيّاغة وتشكيل بدائل تصميمية متنو عة ومبنكرة .

ـ و وتصيليا امكن استتناج ان اعلى نسبة بدائل تصميمية ثبتت من قبل العينة البحثية من ناحية الكتل والهيئات التصميمية

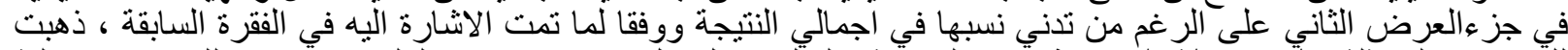

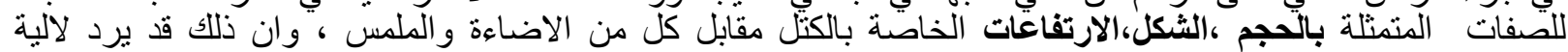

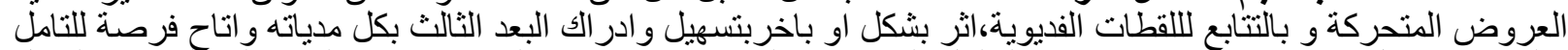

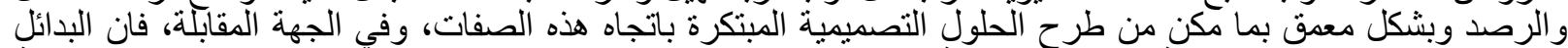

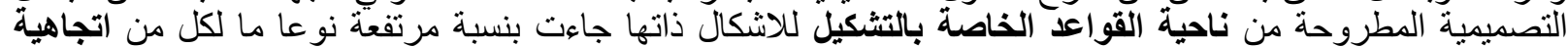

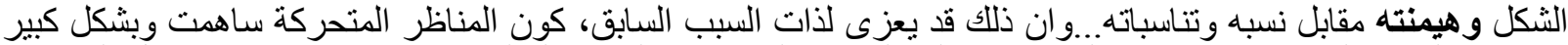

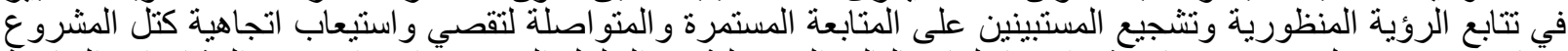

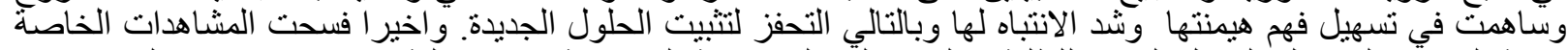

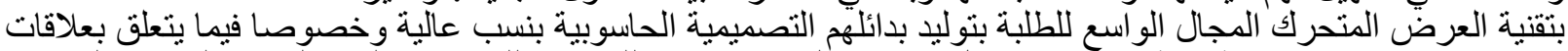

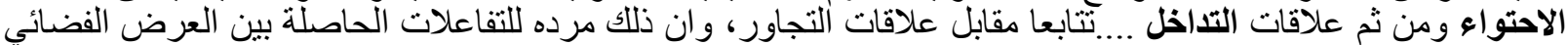

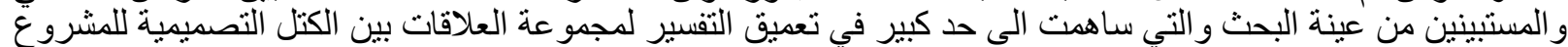

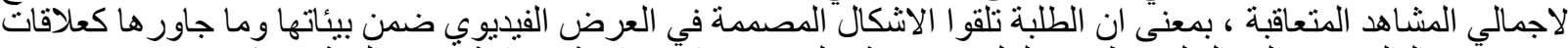
مقصودة وبالتالي فسح المجال لهم بطر ح حلول تصميمية تعلقت بعلاقات فر اغية فضائية غير مالوفة فئ ومبتكرة .

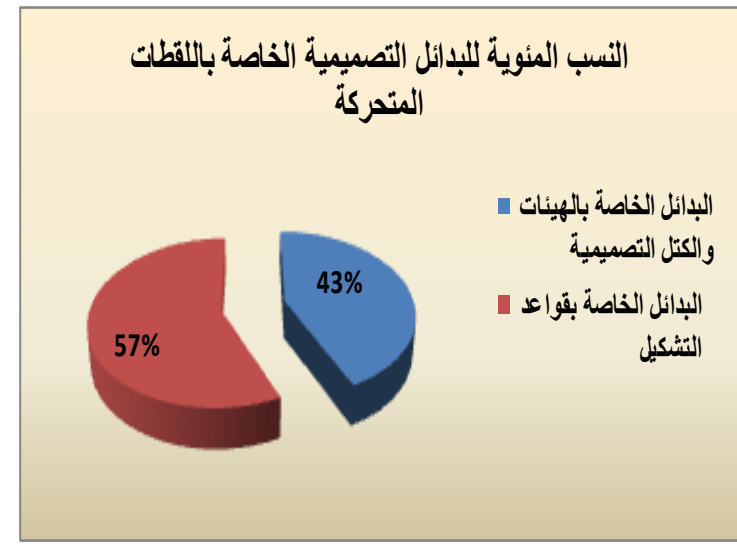

(شكل 20) خلاصة الاستنتاجات النهائية لنسب البدائل التصميمية المطروحة

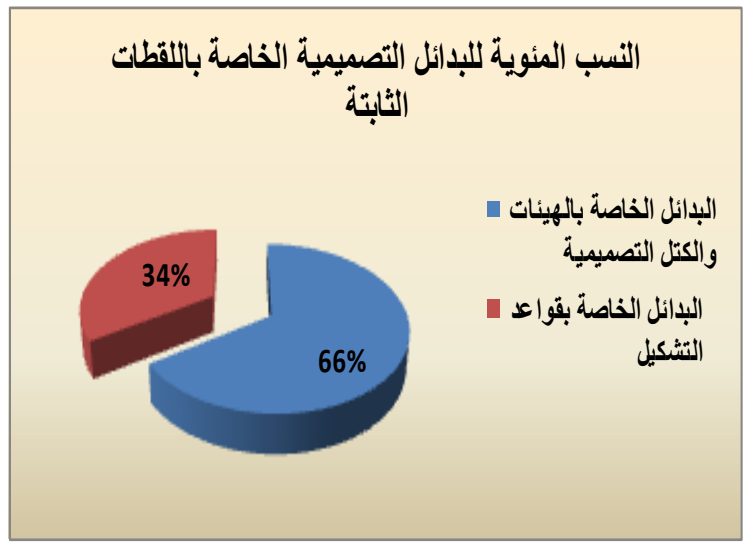

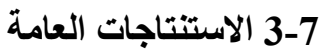

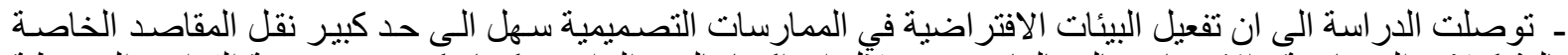

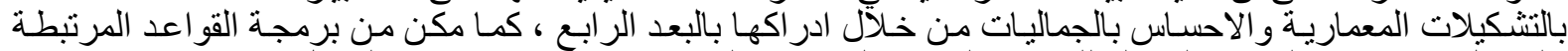
بالتشكيل و استحداث البر امج المؤهلة للتصميم الفر اغي لغات تشكيلية خاصة بها بما يمكن من التجول في بحور ها ومدياتها.

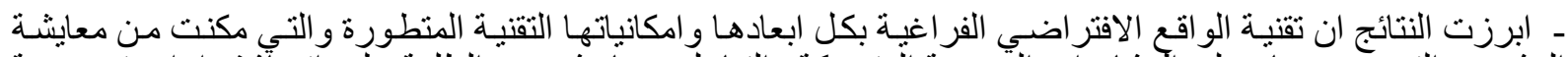

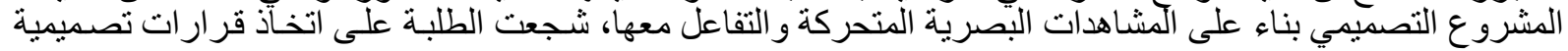




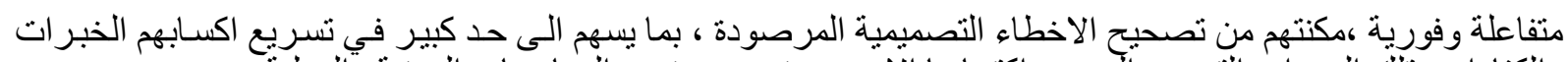

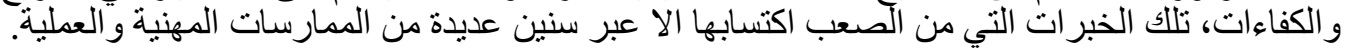

ـ اتاحت الامكانيات الرقمية للعو الم الافتر اضية ، توظيف الحاسوب كاداة تصميمية تفاعلية، لطر ح بدائل تصميمية مبتكرة

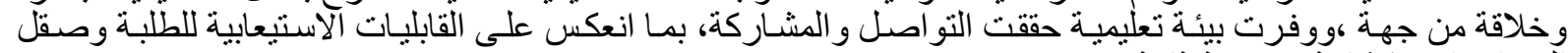
القدر ات الاستكثافية من حهة ثانية.

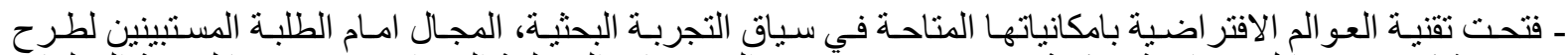

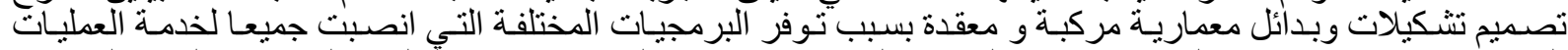

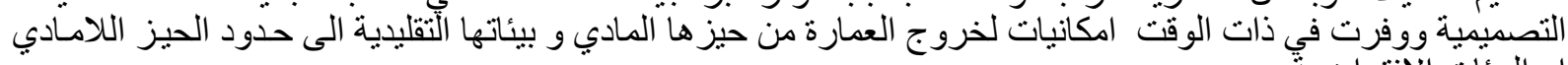
او البيئات الافتراضية.

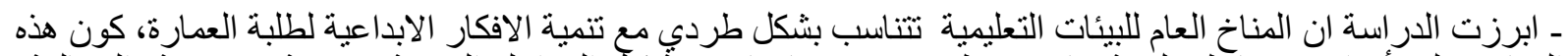

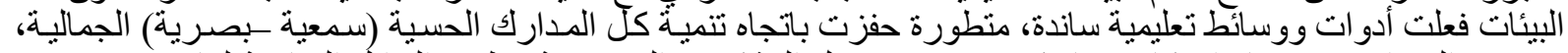

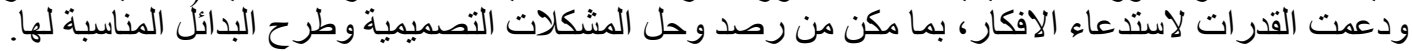

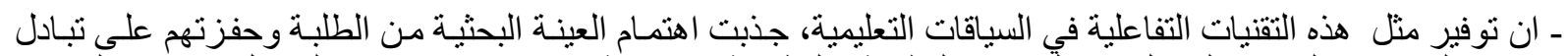

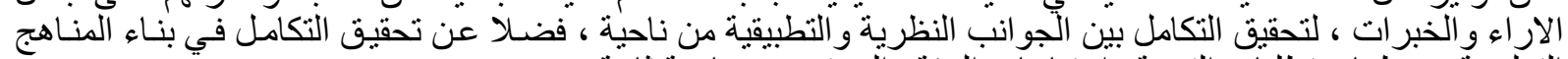
التعليمية وربطها بمتطلبات التمية واحتياجات البئية البئة والمجتمع من ناحية ثانية .

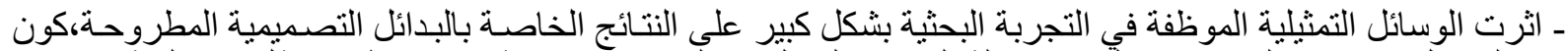

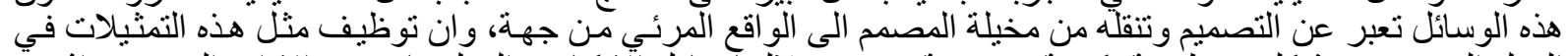

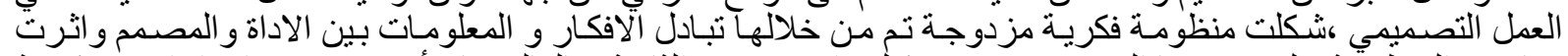

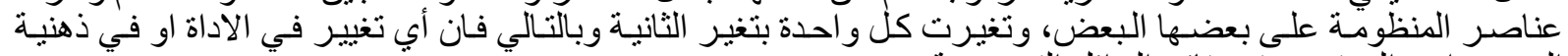
المصمم ادى الى تغيير في نتائج البذائل التصميمية.

التوصيات

1- تو اصل الجهد البحثي في استقر اء التوجهات المستقبلية لو اقع ممارسـة وتعليم التصميم المعمـاري و التاكيد على ربطها

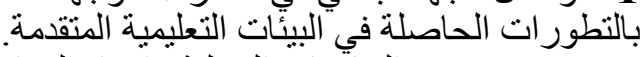

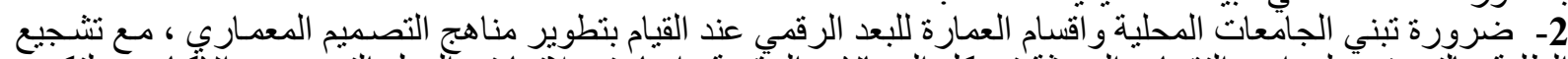

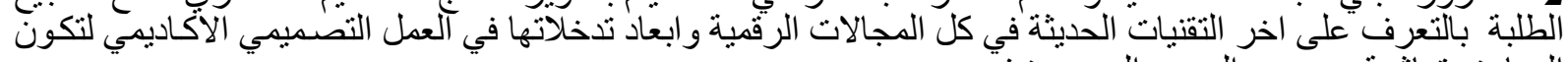

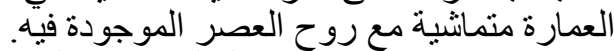

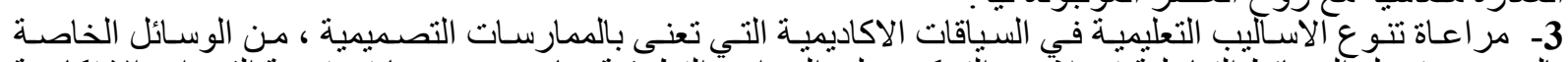

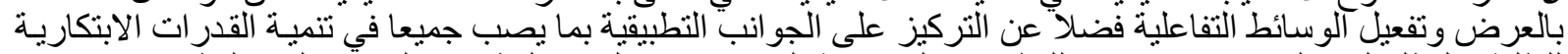

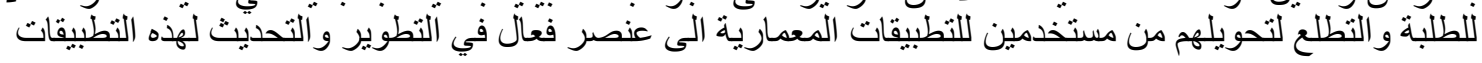

1- أديبادر ، كسرا، 2008، " التحول نحو مجتمع المعرفة وانعكاسات ذلك على الفضاء والتصميم المعماري" ،

http:// www.arch 4all .net

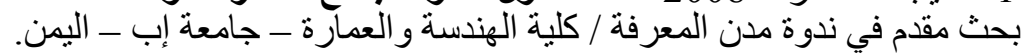

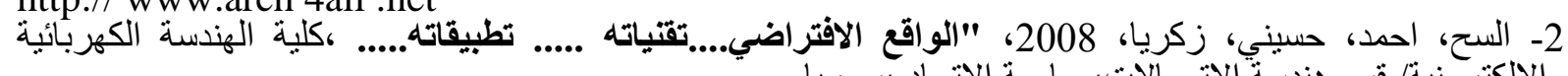
http://www.alhasebat.net والالكترونية/ قسم هندسة الاتصالات، جامعة الاتحاد، كسوريا.

3- جيتس ، بيل / 1998 / " المطوماتية بعد الانترنيت طريق المستقبل " ، ترجمة عبدالسلام رضوان ، عالم المعرفة

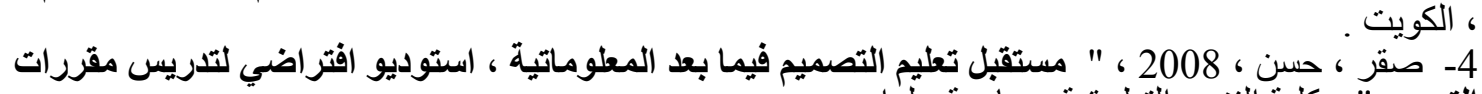

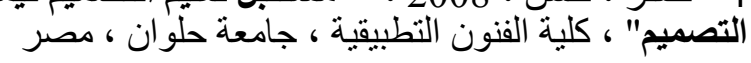

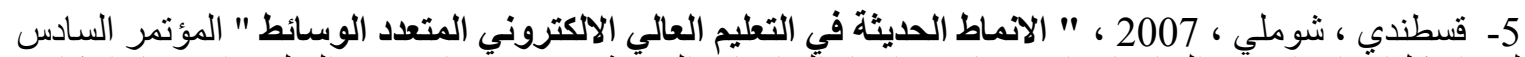

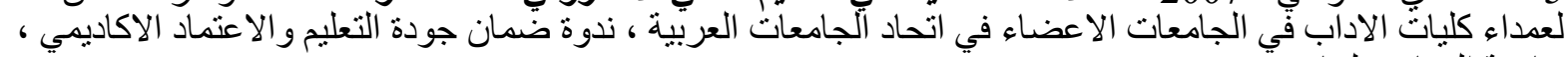

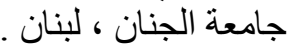




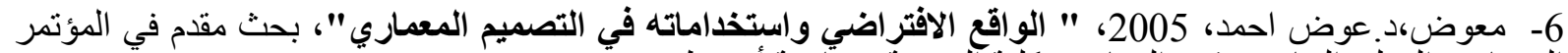

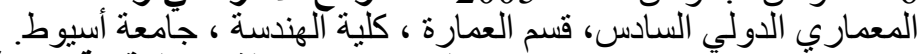

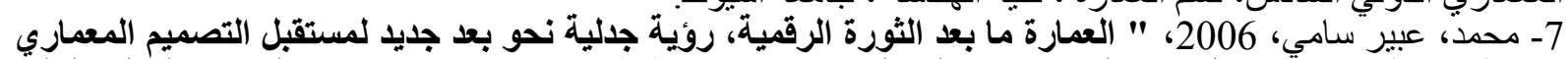

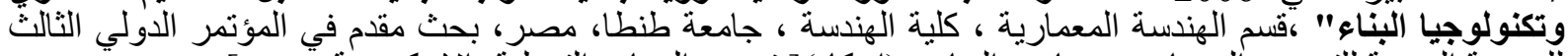

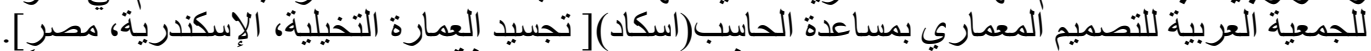

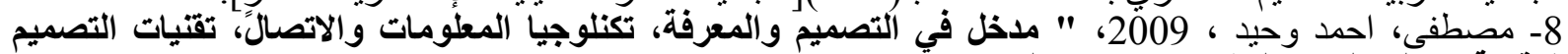

http:// www.ergo-eg.com

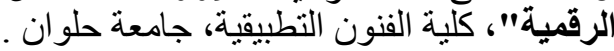
9- المصري، مهران، 2010، " العرولة الواقع الافتراضي/ عالم سحري متفاعل" ، مجلة الباحثون العلمية، مجلة علمية ثقافية

http:// www. Albahethon.com فكرية، العدذ39 أبلِول بتاريخ 2010/9/2.

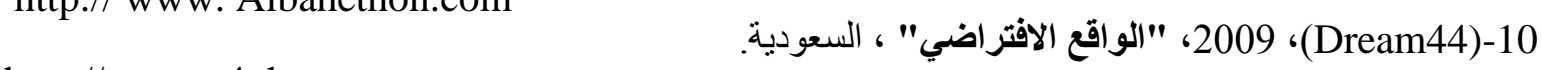

http:// www. 4ph.net

2007، Omran77)-11، عن الكتاب الأصلي لنجوى الخباز، " تعرف على الواقع الافتراضي"، www.THECHEETAWORKSHOP.Com http://

12-طارق،اسماعيل محمد،2006 ، "الاستفادة من تقتيات الكومبيوتر في تصميم بيئات الوسائط المتعددة التعليمية"، علوم

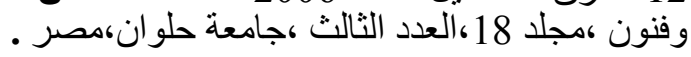

13-دخل الله ،ايمن نجيب،2006"الثورة المعاء المعلوماتية واثزها في التعليم الهندسى المعماري"،كلية الهندسة ،قسم

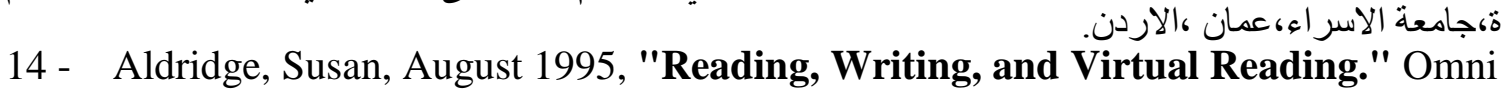

Vol.15, no. 10 p.32.(VR project at west Denton High School in New castle) upon Tyne,

15-"Digital Architecture العمارة الرقمية" , 2012, EI Shamy Designs

England. http:// elshamy designs. Blogspet. Com

16- Mustafa , Ahmed w. , 1994, " The Feasibility of a Computer Aided Product Design Education and Practice System", $2^{\text {nd }}$ International Conference on Computer Engineering Applications, Yanbu. P.51-67.

17- Leach ,Neil , "Digital Towers", in Digital Citiets, Architectral Design magazine, Vol 79,No 4, July /August, 2009.P.62.

18- Maclead,Douglas,"Computer,Virtual Reality" from Progressive Architecture, April,1992,Pento,Pup,Ohio,pp 55-56.

19 -Schwienhorst,K, (2002)",Why Virtual?Why Environment ?",Simulation and Gaming $33(2)$.

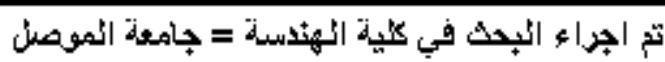

